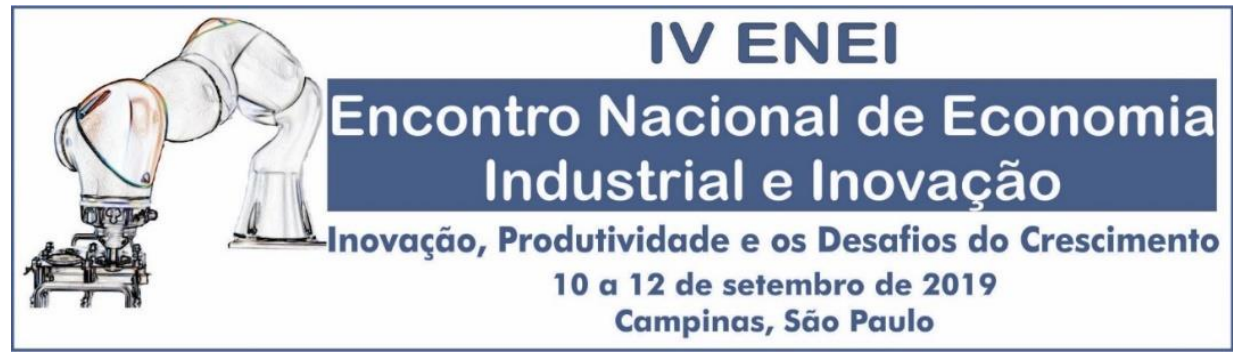

\title{
NOVAS FIRMAS E SPIN-OFFS DE EMPREGADOS NO BRASIL: SOBREVIVENCIA E CRESCIMENTO DE SPIN-OFFS DE OPORTUNIDADE E DE NECESSIDADE ${ }^{\S}$
}

Thiego Gonçalves Ferreira

\section{RESUMO}

Embora seja fato estilizado que novos spin-offs de empregados apresentem taxas de sobrevivência superiores a de demais firmas entrantes, a literatura a respeito do crescimento dessas firmas, além de ser escasso, não parece convergir. Utilizando a ligação empregado-empregador da RAIS Trabalhador para o período de 2006 a 2015, identifico spin-offs e segmento-os entre os tipos pulled (oportunidade) e pushed (necessidade), quando a firma pai que deu origem continua ativa ou não, respectivamente. Mesmo controlando por características dos trabalhadores, das firmas e de setores, os resultados sugerem que spinoffs brasileiras tem maior taxa de crescimento e sobrevivência se comparada a outros entrantes. Quando se compara entre os tipos pulled e pushed spin-offs, ambos têm probabilidade de sobrevivência semelhantes. Porém, pushed cresce a taxas inferiores do que os demais entrantes, ao contrário das pulled spin-offs. Ainda, encontra-se evidências de que spin-off tem maior probabilidade de se tornar empresa gazela, e que a escolha do regime tributário diferenciado (SIMPLES) tem um importante papel para sobrevivência das empresas, porém ao custo de limitar o crescimento e a geração de empregos.

Palavras-chaves: spin-off de empregados; sobrevivência de firmas; crescimento de firmas; empreendedorismo; gazelas

Classificação JEL: L26, L25, J21, J24

Área ABEIN: 1.1 Dinâmicas industriais setoriais e dos sistemas de produção

\begin{abstract}
Although a stylized fact in the literature is that employee spin-off has higher survival likelihood compared to other entrants, their growth advantage is not clear in the literature. Using linked employeremployee data for Brazil we identify spin-off and differentiate between pulled (opportunity) and pushed (necessity) spin-offs, when the parent firm is active or not, respectively. Controlling for worker, firm and sector characteristics, results suggest that Brazilian spin-offs have higher growth and survival rates compared to other entrants. When comparing pulled and pushed spin-offs, both have similar survival rates, but pushed spin-offs have lower growth rates than regular entrants and pulled spin-offs. Besides, there is evidence that spin-off is more likely to become gazelle company and that SIMPLES Nacional has import role in keeping firms alive but limiting growth and jobs generation.
\end{abstract}

Key words: employee spin-off; firm survival; firm growth; entrepreneurship, gazelles.

\footnotetext{
$\S$ As opiniões expressas não representam a opinião oficial das instituições a que o autor está vinculado. O acesso aos dados da RAIS se deu pelo acesso via programa de estatísticas do MTE junto ao IE/UFRJ, mantida a não identificação das informações. A manipulação, interpretação e conclusões baseados nos dados não pode ser atribuído ao MTE. O Instituto Brasileiro de Geografia e Estatística (IBGE) está isento de qualquer responsabilidade por opiniões, informações, dados e conceitos emitidos neste artigo, que são de exclusiva responsabilidade do autor.

- PPGE/IE/UFRJ e IBGE
} 


\section{INTRODUÇÃO}

Novas firmas possuem um importante papel na dinâmica econômica que envolve, dentre outras coisas, uma permanente entrada e saída de firmas. Conseguir sobreviver (e eventualmente, crescer) neste ambiente concorrencial resgata o debate sobre quais são os determinantes para a sobrevivência e crescimento das firmas. Uma característica que tem se mostrado importante preditora é a maneira como as firmas se originam e, neste sentido, uma classe especial de novas firmas tem ganhado a atenção nos últimos anos: aquelas que têm origem através de spin-off de empregados ${ }^{1}$.

Firmas perdem empregados que, por sua vez, saem individualmente ou em conjunto para fundar suas próprias empresas. Spin-offs diferenciam-se de outras firmas entrantes por um conjunto de fatores, dentre eles, pela maior possibilidade de herdar conhecimento e tecnologia da firma incumbente (KLEPPER e SLEEPER, 2005); por possuir menores custos iniciais de recrutamento - searching cost (ROCHA e VARUM, 2018); pela existência de uma rede de contato (clientes e colegas de trabalho) estabelecida antes da formação da spin-off (AGARWAL et al, 2004); e, em alguns casos, o fato de a spinoff nascer já com uma demanda relativamente garantida, situação em que a firma pai é seu próprio cliente. Essas características motivaram diversos estudos empíricos que tornaram fato estilizado o resultado de que spin-offs de empregados possuem maior probabilidade de sobreviver do que as demais firmas entrantes (ERIKSSON e KUHN, 2006; MUENDLER et al., 2012; ANDERSSON e KEPPLER, 2013; FACKLER et al., 2016).

Entretanto, os estudos sobre crescimento orgânico de spin-offs de empregados não parecem convergir, diferentemente do que ocorre com a sobrevivência. Enquanto alguns autores verificam que spin-offs experimentam no curto prazo taxa de crescimento maior do que a taxa das demais firmas entrantes (ANDERSSON e KEPPLER, 2013; FRYGES et al., 2014), outros autores não confirmam esta tendência. Por exemplo, mesmo controlando um amplo conjunto de variáveis relativas ao capital humano, à firma e a características setoriais, Sarada e Tocoian (2018) afirmam que novas firmas com empregados previamente conectados - proxy para spin-off de empregados - apresentam maior probabilidade de sobrevivência, porém menor taxa de crescimento no curto prazo.

Dada a aparente divergência e ao fato de existirem poucos estudos sobre o tema aplicados ao Brasil, este trabalho pretende contribuir com a literatura de três formas. Primeiro, analisando, para um período recente das empresas formais brasileiras, a taxa de crescimento de spin-offs em relação à taxa das demais empresas entrantes, em seus anos iniciais (e críticos) de operação. Além disso, apresenta evidências entre relação da formação a spin-off e o nível de atividade econômica.

Segundo, explora-se a heterogeneidade das spin-offs, estudando a diferença de performance (sobrevivência e crescimento) entre spin-offs do tipo pulled (quando a firma pai, que deu origem ao spinoff, continua em operação) e pushed (quando a firma pai deixa de operar no ano mesmo de surgimento do spin-off). A maior parte da literatura internacional tem verificado que a taxa de sobrevivência de pulled spin-off é superior à taxa de pushed spin-off. É o caso dos estudos aplicados às firmas da Dinamarca (ERIKSSON e KUHN, 2006), Suécia (ANDERSSON e KLEPPER, 2013) e Alemanha (FACKLER et al., 2016). Por outro lado, Portugal apresenta comportamento contrário (ROCHA, 2014, 2015), com pushed spin-off apresentando maior taxa de sobrevivência do que pulled spin-off.

A terceira contribuição com a literatura consiste em estudar a probabilidade de spin-offs de empregados e gazelas. As gazelas são caracterizadas por serem firmas jovens e de crescimento acelerado. Elas são importantes por contribuírem para o crescimento econômico e por gerarem relativamente muitos empregos (HENREKSON e JOHANSSON, 2010; SENDEROVITZ et al., 2012), especialmente no Brasil (SANTOS et al., 2014 apud ESTATÍSTICAS ..., 2017). Uma questão é se o fato de a empresa nascer de um spin-off aumenta a probabilidade de se tornar gazela. As evidências existentes - de melhor desempenho das spin-offs - não costumam ser relacionada com as empresas gazelas.

\footnotetext{
${ }^{1}$ Conforme será apresentado no capítulo 2, o termo spin-off de empregado (ou employees spin-off) possui conceito específico e, a rigor, não é idêntico ao simples termo spin-off. Porém, por questão de simplicidade, trataremos como sinônimo em diversas partes do texto.
} 
As análises são realizadas a partir do amplo conjunto de dados longitudinais em painel da RAIS identificada, que compreende o universo de todas as empresas formalmente constituídas no país e que relaciona empregados a empregadores durante o período de 2006 a 2015. Além disso, os modelos construídos com base nesses dados utilizam variáveis de controle de capital humano e de características da firma, ambas no momento da entrada. Elas permitem avaliar se, mesmo após diversos controles estatísticos, a informação observável por tipo de spin-off ainda explica de forma significativa as taxas de sobrevivência e de crescimento.

Esta pesquisa possui importantes implicações para empreendedores, empresas, policy-makers e profissionais de mercado de crédito e capital. Empreendedores sabem que o sucesso da firma, especialmente nos anos iniciais de operação, depende da definição de uma boa estratégia e estrutura organizacionais, porém elas não estarão completas se eles ignorarem as dotações de capital humano dos primeiros empregados da firma (BAPTISTA et al., 2014).

Quanto às empresas brasileiras, não é prática solicitarem aos seus empregados que assinem cláusulas de não-competição, por mera questão legal ${ }^{2}$. Há países, por outro lado, em que tais cláusulas são permitidas. Elas cláusulas dificultam a mobilidade interfirmas dos empregados e a capacidade de eles criarem spin-off de empregados. Ao chamar a atenção para este tema, o estudo permitirá com que as empresas conheçam o quanto desses movimentos de fluxo dos trabalhadores representa da dinâmica microeconômica e, dependendo da relevância, possam reavaliar essa cultura de não adotar cláusulas de não-competição. Ao mesmo tempo, por se tratar de uma mudança que pode desencorajar empregados e empreendedores - consequentemente, a geração de empregos -, os governos precisam ter uma opinião formada acerca desse assunto. Outro aspecto a respeito dos policy-makers é que este estudo pode fornecer insights para onde eles possam concentrar o apoio governamental e, assim, novas firmas contribuírem com o emprego e competitividade.

Por fim, o trabalho serve como mais um instrumento para análises de risco de crédito e de mercado de capitais, ao conhecermos a diferença de performance entre os spin-offs e demais entrantes, bem como sabermos o comportamento dos dois tipos de spin-offs. Afinal, o risco de crédito envolve saber identificar a probabilidade de um tomador de crédito honrar com as dívidas contraídas e, naturalmente, isto passa por reconhecer qual tipo de firma tem maior probabilidade de sobrevivência. Quanto para os investidores no mercado de capital o importante é que a firma apresente o maior crescimento potencial.

Um aspecto em comum entre todos os interessados supracitados é a necessidade de diferenciar os tipos de entrantes. Conhecer as características dos tipos de spin-off, porém, não conseguir identificá-los na prática seria incompleto. Neste sentido, este trabalho contribui na compreensão sobre spin-off brasileiras e seus tipos pulled e pushed utilizando características mais facilmente observáveis. Até então, os estudos realizados para o Brasil sobre spin-off ou não apresentam indicadores de performance (RIBEIRO et al., 2017) ou não segregam os tipos de spin-off segundo pulled e pull (MUENDLER et al., 2012; SARADA e TOCOIAN, 2018). Embora estes utilizem outras segmentações de spin-off, elas geralmente são menos observáveis ${ }^{3}$.

O trabalho está divido em sete capítulos, sendo o primeiro essa introdução. O segundo aborda brevemente o que sabemos sobre spin-offs de empregados e onde ele se encaixa na literatura geral de spin-offs. Além disso, realiza uma revisão da literatura empírica de spin-off de empregados, incluindo

\footnotetext{
${ }^{2} \mathrm{Na}$ ótica da defesa da concorrência, sendo o ato de criação da firma ou entrada no mercado importante para competição, barreiras à entrada como cláusulas de não-competição podem ser contestadas pelo Conselho de Administrativo de Defesa Econômica - CADE.

${ }^{3}$ Muendler et al. (2012) segmenta os spin-offs em quarter-worker spin-off e divestiture, que são categorizados segundo o número e a proporção de empregados (em relação a firma pai e ao spin-off). Sarada e Tocoian (2018), ao analisarem a sobrevivência e o crescimento de empregados, eles não categorizam as spin-offs, mas propõe um indicador de conexão entre empregados que utiliza as mesmas variáveis de Muendler et al. (2012). Acontece que a informação sobre número de empregados da spin-off, da firma pai que deu origem ao spin-off, e da quantidade que saiu da firma para abrir o spin-off afins de calcular a proporção são informações que geralmente não estão disponíveis para quem está fora dessas empresas. Por outro lado, uma vez identificada que a nova firma se trata de um spin-off, segmentá-la em pulled e pushed basta saber se a firma pai continua ou não em operação.
} 
indicadores de performance mais utilizados e principais determinantes de sobrevivência e crescimento de spin-offs.

O terceiro capítulo trata dos dados e metodologia. Apresentam-se as características dos microdados utilizados e os metodologia para identificação de spin-off. No capítulo seguinte, realiza-se uma análise descritiva das variáveis, em busca de ressaltar as principais fontes de diferenças observadas entre os três tipos de firmas entrantes: pulled spin-off, pushed spin-off e demais firmas. O quinto capítulo traça a estratégia empírica e o sexto analisa os resultados. Por fim, tem-se a conclusão e, por fim, as referências bibliográficas.

\section{SPIN-OFF DE EMPREGADOS E LITERATURA RELACIONADA}

Fatores históricos. O fenômeno spin-off teve início na década de 60, através das indústrias de alta tecnologia de semicondutores (FERREIRA et al., 2007). Firmas deram origem a spin-offs que, por sua vez, originaram novas spin-offs. A grande quantidade de firmas e a relativa proximidade entre elas, foi fundamental para a expansão do Vale do Silício, Califórnia. Um conhecido estudo de caso é o da Fairchild Semicondutor, fundada em 1957 por oito empregados que deixaram a empresa Shockley Semicondutor, e já deu origem a mais de 100 spin-offs de empregados em diferentes setores. Dentre elas, as mais importantes fabricantes de microprocessadores Intel e AMD (KLEPPER, 2007). Apesar de spinoffs terem surgido com maior visibilidade em setores de alta tecnologia, sua presença em outros setores ocorre regularmente (GARVIN, 1983).

Correntes teóricas de spin-offs. O conceito de spin-off é bastante diverso na literatura, que depende da métrica disponível ou do objetivo do estudo. Em uma revisão mais ampla da literatura, Ferreira et al. (2017, p. 290) estabelece que o conceito de spin-offs tem sido usado para caracterizar a formação de novas empresas basicamente de três maneiras: spin-off empreendedora, spin-off acadêmica e spin-off corporativa, cada um com diferentes características.

Um spin-off empreendedor ocorre quando um empregado, independentemente da motivação, deixa seu atual empregador para iniciar um novo empreendimento (KLEPPER e SLEEPER, 2005). Um bom exemplo é a criação da empresa SAP no setor de $\mathrm{TI}^{4}$. Outro tipo é o spin-off acadêmico, que se refere a uma nova firma fundada por um pesquisador que deixa a universidade ou unidade de pesquisa para criar uma start-up. Esta classe não será tratada aqui. Por fim, o fenômeno spin-off corporativo (também chamado de spin-out), em essência, surge quando uma firma é dividida em pequenas unidades independentes, servindo tipicamente como método para desmembrar negócios não relacionados.

A literatura empírica de spin-off de empregados pode ser enquadrada tanto na literatura de spin-off empreendedor quanto corporativo. E, por esta razão, trataremos daqui para frente estes três conceitos como sinônimos de spin-off.

Pulled e pushed spin-offs. A definição dos conceitos acima não entra no mérito do que leva o empregado a sair da firma e abrir um novo empreendimento. Porém, considerar se os motivos se tratam de oportunidade ou simples necessidade permitirá compreender ainda melhor a trajetória das firmas.

A história da SAP está longe de ser a única. Spin-offs como essa tem sido considerada alavancas para inovação e promoção da dinâmica industrial em inúmeros mercados (BUENSTORF, 2007). Essa busca por um novo negócio motivado pela identificação de oportunidade deu origem ao termo opportunity spin-off ou pulled spin-off 5 .

Acontece que nem todos os spin-offs, seja por parte dos empregados ou por decisão da própria firma, surgem pela identificação de oportunidades. Muitos spin-offs surgem de necessidades, o que explica o termo necessity spin-off ou pushed spin-off. Choques adversos nas firmas incumbentes, tais

\footnotetext{
${ }^{4}$ Fundada em 1972 por cinco empregados que se demitiram da IBM para iniciaram um novo empreendimento e que hoje possui 95 mil empregados em mais de 130 paises (SAP, 2018)

${ }^{5} \mathrm{O}$ que não quer dizer que se trata apenas de uma decisão unilateral por parte do empregado. Pulled spin-off pode também capturar o resultado da decisão estratégica de uma firma incumbente que cria uma spin-off para desenvolver novas tecnologias, entrar em novos mercados, criar complementariedades ou focar no core business delas.
} 
como encerramento das atividades, downsizing massivo ou mudanças na gestão podem fazer com que um empregado (ou alguns deles) deixem a firma e criem sua própria empresa (ROCHA, 2014, p. 174).

Para Buenstorf (2007), necessity spin-offs desempenham um papel importante na dinâmica de mercados competitivos, ao limitarem a depreciação do capital humano originada por choques adversos a firmas individuais.

Um comparativo da literatura empírica de spin-off de empregados. Diante das inúmeras ramificações de estudos sobre spin-off, este artigo se debruça sobre apenas uma das facetas do conceito de spin-off, o de spin-off de empregados, segundo sua heterogeneidade por pulled e pushed. E mesmo com essa restrição de escopo, ainda há uma diversificada literatura, em decorrência das maneiras de se identificar spin-offs de empregados e sua métricas de performance. Por esta razão, serão revisados apenas os trabalhos que adotam o número de empregados como métrica de performance, bem como, aqueles que utilizam para identificação de spin-off, principalmente, a técnica de worker flow linked employeeemployeer (BENEDETTO, 2004) ${ }^{67}$.

A técnica de Benedetto consiste, basicamente, em classificar as firmas entrantes de acordo com a informação do fluxo dos trabalhadores entre a firma anterior (de onde vem o empregado) e a sucessora (para onde vai o empregado). Através de informações longitudinais para trabalhadores em uma base dados de empregador-empregado, as firmas entrantes são classificadas em simples "mudança de identidade", "fusão/aquisição" ou "spin-offlbreakout".

Em linhas gerais, a identificação das firmas entrantes ocorre da seguinte forma. São analisadas, em determinado ano contra o ano anterior, as condições das firmas entrantes (firma sucessora), da firma pai (firma antecessora) e dos empregados. As firmas antecessoras podem sair ou continuar em operação. As firmas sucessoras podem iniciar ou continuar em operação. Quanto aos empregados, determinado percentual deles (em relação a antecessora) vai para a firma sucessora e outro percentual (em relação à sucessora) chega da firma antecessora. Chamarei esses percentuais de pontos de corte. A combinação dessas condições fornece as classificações das firmas.

Os trabalhos empíricos fundamentados nessa técnica, geralmente, analisam, para diferentes países, a probabilidade de sobrevivência e/ou a taxa de crescimento de firmas entrantes, comparando spin-offs à não-spin-offs. Há, ainda, aqueles que estudam os spin-offs segundo seus tipos pulled e pushed.

O Quadro 2.1 mostra um comparativo entre recentes literaturas de spin-off de empregados. Elas se diferenciam segundo: os dados de qual país o estudo foi aplicado; os tipos de entrantes, inclusive, entre aqueles que subdividem spin-offs em pulled e pushed; os indicadores de performance, que podem ser análise de sobrevivência ou crescimento da firma; a estratégia empírica utilizada; e os resultados obtidos para cada indicador de performance, segundo a estratégia empírica adotada.

Eriksson e Kuhn (2006) apresentam evidências de que a relação entre a firma pai e a firma descendente afeta a probabilidade de sucesso dos spin-offs (firma descendente). Utiliza-se um amplo conjunto de dados longitudinais empregador-empregado que cobre toda Dinamarca entre os anos de 1981 e 2000. As firmas são categorizadas em pulled spin-off, pushed spin-off e demais. Os pontos de cortes dos autores são de $50 \%$ e apenas firmas de pequeno porte, com 2 a 10 empregados, são consideradas. As demais, são excluídas da amostra, dentre elas, as que apenas mudaram de identidade (shifted ID) ou divested.

Baseada nas categorizações supracitadas, os Eriksson e Kuhn (2006) analisam os padrões de entrada e saída das firmas, assim como realizam uma análise de sobrevivência. A entrada das fïrmas

\footnotetext{
${ }^{6}$ Embora não utilizem a mesma técnica de Benedetto, também serão abordados os trabalhos de Rocha (2014) e Sarada e Tocoian (2018). O primeiro, por explorar uma interessante comparação apenas entre pulled e pushed spin-off para Portugal. O segundo, por analisar o crescimento de spin-offs de empregados brasileiros, até então não abordados nos estudos anteriores de spin-off para firmas brasileiras.

${ }^{7}$ A técnica de Benedetto consiste, basicamente, em classificar as firmas entrantes de acordo com a informação do fluxo dos trabalhadores entre a firma anterior (de onde vem o empregado) e a sucessora (para onde vai o empregado). Através de informações longitudinais para trabalhadores em uma base dados de empregador-empregado, as firmas entrantes são classificadas em "mudança de identidade", "fusão/aquisição" ou "spin-off/breakout".
} 
apresenta relação com o ciclo econômico e características individuais dos empregados. Ao analisar como os padrões de criação da firma variam com relação aos ciclos econômicos, os autores encontram evidências de que em períodos de crescimento econômico há menos atividades de spin-offs. Por outro lado, em períodos de recessão ou estabilidade estão associados a maior formação de spin-offs. Quanto aos padrões de saída das firmas, observa-se que elas apresentam características bastante distintas. Porém, utilizando controles de características observáveis, os autores concluem que spin-offs tem maior probabilidade de sobreviver (pulled e pushed $>$ demais). Ainda, dependendo do ponto de corte, essa probabilidade pode ser ainda maior no curto prazo se o spin-off entrar na mesma indústria da firma incumbentes. Um indicativo de que há uma espécie de catch up dos demais entrantes em relação aos spinoffs.

Quadro 2.1 - Literaturas recentes de spin-off de empregados.

\begin{tabular}{|c|c|c|c|c|}
\hline Autores & Dados & Tipos de entrantes & $\begin{array}{c}\text { Indicadores de } \\
\text { performance }\end{array}$ & Resultados empiricos \\
\hline $\begin{array}{l}\text { Eriksson and } \\
\text { Kuhn (2006) }\end{array}$ & $\begin{array}{c}\text { Dinamarca } \\
\text { (1981 a 2000) }\end{array}$ & $\begin{array}{l}\text {-Pulled spinoff } \\
\text {-Pushed spinoff } \\
\text {-Demais } \\
\end{array}$ & Sobrevivência & Pulled $>$ Pushed $>$ Demais \\
\hline $\begin{array}{l}\text { Muendler et al. } \\
(2012)\end{array}$ & $\begin{array}{c}\text { Brasil } \\
(1995 \text { a 2001) }\end{array}$ & \begin{tabular}{|l}
-Spinoff \\
-Diverstitures \\
-Firmas sem pais
\end{tabular} & Sobrevivência & Divestiture $>$ Spinoff $>$ Firmas sem pais \\
\hline \multirow{2}{*}{$\begin{array}{l}\text { Andersson e } \\
\text { Klepper (2013) }\end{array}$} & \multirow{2}{*}{$\begin{array}{c}\text { Suécia } \\
\text { (1993 a 2005) }\end{array}$} & \multirow{2}{*}{\begin{tabular}{|l}
-Pulled spin-off \\
-Pushed spin-off \\
-Non-employed \\
-Divestiture \\
\end{tabular}} & Sobrevivência & Pulled $>$ Divested $>$ Pushed $*>$ Demais $>$ Non-employed \\
\hline & & & Crescimento & Pulled $>$ Pushed $>$ Divestiture* $>$ Demais $>$ Non-employed. \\
\hline \multirow{2}{*}{ Rocha (2014) } & \multirow{2}{*}{$\begin{array}{l}\text { Portugal (1992 } \\
\text { a 2007) }\end{array}$} & \multirow{2}{*}{$\begin{array}{l}\text {-Pulled spinoff } \\
\text {-Pushed spinoff }\end{array}$} & Sobrevivência & Pushed $>$ pulled \\
\hline & & & Crescimento & Pushed $\sim$ Pulled \\
\hline $\begin{array}{l}\text { Fackler et al. } \\
(2016)\end{array}$ & $\begin{array}{c}\text { Alemanha } \\
\text { (1977 a 2008) }\end{array}$ & $\begin{array}{l}\text {-Pulled spinoff } \\
\text {-Pushed spinoff } \\
\text {-Demais entrantes }\end{array}$ & Sobrevivência & Pulled $>$ Pushed $>$ Demais \\
\hline $\begin{array}{l}\text { Ribeiro et al. } \\
\text { (2017) }\end{array}$ & $\begin{array}{c}\text { Brasil } \\
\text { (2012 a 2014) }\end{array}$ & $\begin{array}{l}\text {-Pulled spinoff } \\
\text {-Pushed spinoff } \\
\text {-Merge/aquisition } \\
\text {-Shift ID } \\
\text {-Demais entrantes } \\
\end{array}$ & Não há & Não há \\
\hline \multirow{2}{*}{$\begin{array}{l}\text { Sarada e } \\
\text { Tocoian (2018) }\end{array}$} & \multirow{2}{*}{$\begin{array}{c}\text { Brasil } \\
(1995 \text { a 2001) }\end{array}$} & \multirow{2}{*}{$\begin{array}{l}\text { Mensurado pelo indicador de } \\
\text { concentração HHI }\end{array}$} & Sobrevivência & Spinoff > Não-spinoff \\
\hline & & & Cres cimento & Não-spinoff > Spinoff \\
\hline
\end{tabular}

Fonte: Elaboração própria.

Notas: Lê-se o símbolo '> ' como, por exemplo, em Eriksson e Kuhn (2006), pulled apresentou performance de sobrevivência superior à firma pushed. O conceito do HHI utilizado neste quadro é detalhado no Erro! Fonte de referência não encontrada..

Com alguma proximidade ao trabalho de Eriksson e Kuhn (2006), mas incluindo firmas com mais de 10 empregados e a entrada de unidades de firmas existentes, Muendler et al. (2012) realizam o primeiro estudo aplicado ao Brasil sobre spin-off de empregados. Através dos dados da RAIS para o período de 1995 a 2001, os autores analisam padrões de entrada e como se comportam as taxas de sobrevivência dessas firmas. Os entrantes são classificados em três tipos: spin-off de empregados (denominada de quarter-workforce spin-off, pois consideram o ponto de corte de $25 \%$ ), diverstiture e firmas não relacionadas (que chamaremos de 'demais'). Os autores não levam em conta a continuidade da firma pai na definição dos entrantes, de modo que não analisam uma visão de pulled e pushed spin-off. Muendler et al. (2012) também encontram evidências do melhor desempenho dos spin-offs: no período de cinco anos, spin-off de empregados possuem maior probabilidade de sobrevivência do que firmas sem pais.

Andersson e Klepper (2013) estudam, para o período de 1993 a 2005, a taxa de formação, as características e a performance de diferentes tipos de novas firmas suecas. Também são estudados os determinantes da transição dos empregados, bem como os resultados são comparados com os países da 
Dinamarca (ERIKSSON e KUHN, 2006) e Brasil (MUENDLER et al., 2012). Diferentemente dos estudos anteriores, os autores analisam não apenas a sobrevivência, mas também a taxa de crescimento. Os resultados continuam em linha com os estudos anteriores. Por exemplo, que spin-offs, de uma maneira geral, performam melhor do que as demais firmas entrantes, especialmente se a firma pai continua em operação. O que é apontado como evidência de que spin-offs herdam competências e conhecimento para explicar uma superioridade temporária ${ }^{8}$ em relação às demais firmas. Além disso, os autores encontram que spin-offs que entram na mesma indústria da firma pai desempenham melhor do que outros spin-offs. Para análise de crescimento, os resultados são semelhantes ao da sobrevivência, com pulled superior às demais firmas.

Até aqui, os estudos mostraram que spin-offs apresentam taxas de sobrevivência e crescimento superiores à média. Além disso, aqueles que consideraram a heterogeneidade dos spin-offs, indicaram de forma unânime que pulled spin-off possuem tanto maior probabilidade de sobrevivência quanto taxa de crescimento de empregados superior a pushed spin-offs. Rocha (2014), porém, apresenta evidências no sentido de que não é possível afirmar sobre a superioridade das pulled spin-off. Utilizando registros de Portugal do período de 1992 a 2007 e modelos que comparam entre si somente os dois tipos de spin-off, após realizado os devidos controles, a autora mostra que pushed spin-off apresenta maior probabilidade de sobreviver do que pulled spin-off. Já para a taxa de crescimento o modelo não apresentou evidências significativas dessa superioridade.

Fackler et al. (2016) dedicam-se a analisar a taxa de sobrevivência das firmas privadas na Alemanha levando em conta a heterogeneidade de spin-offs em pulled e pushed. Os autores seguem, em grande parte, a abordagem de Eriksson e Kuhn (2006) para identificação de spin-offs. Os resultados estão em linha com as conclusões apontadas nos trabalhos para Dinamarca (ERIKSSON e KUHN, 2006), Brasil (MUENDLER et al., 2012) e Suécia (ANDERSSON e KLEPPER, 2013).

Ribeiro et al. (2017) baseiam-se de forma mais fidedigna ao trabalho de Benedetto et al. (2007) e exploram não apenas a formação de spin-offs. Utilizando dados mais recentes do que Muendler et al. (2012) e Sarada e Tocoian (2018), os autores mensuram a dinâmica das firmas brasileiras através do fluxo de empregados de 2012 a 2014. Uma das conclusões é que 3,9\% das firmas surgem de spin-off, bem como no Brasil as spin-offs do tipo pulled é muito mais frequente do que nos EUA. Pela primeira vez, os spin-offs dos tipos pulled e pull são explorados diretamente com os dados brasileiros. Entretanto, na mesma linha de Benedetto et al. (2007), não se analisa a performance das firmas.

Por fim, temos o trabalho de Sarada e Tocoian (2018), que dão mais um passo no que tange a performance de spin-offs de firmas brasileiras. Os autores analisam não apenas a sobrevivência, como Muendler et al. (2012), mas também o crescimento de empregados das spin-offs em relação às demais firmas entrantes.

Partindo do mesmo conjunto de dados de Muendler et al. (2012) e utilizando um indicador, baseado no HHI (Herfindahl Hirschman Index), que mede a conexão prévia entre os empregados, os autores mostram que a estrutura de relacionamento dos empregados é um forte preditor para a sobrevivência e crescimento das firmas, inclusive quando controlados por características de capital humano, da firma e setorial. Quanto maior a conexão prévia entre os primeiros empregados, maior a probabilidade de sobrevivência, porém menor é a taxa de crescimento no curto prazo. Apesar de os autores não utilizarem diretamente a técnica de Benedetto et al. (2007), é razoável inferir que os spin-offs de empregados partilham de resultados semelhantes. De modo que, no curto prazo, poderíamos dizer que spin-offs apresentam maior taxa de sobrevivência do que não spin-offs e a taxa de crescimento, com spinoffs crescendo menos do que não-spin-offs.

\footnotetext{
${ }^{8}$ É dita temporária pois após 3 anos essa vantagem desaparece, sugerindo que spin-off herdam dos pais um conhecimento tácito e dificilmente imitável, mas que no longo prazo, tal conhecimento específico se dilui a medica que novas firmas entram no mercado e aprendem o conhecimento através da experiencia da indústria (ANDERSSON e KLEPPER, 2013, p. 277).
} 
Diante da revisão de recentes literaturas sobre spin-offs de empregados observa-se que existem poucos estudos de spin-offs de empregados aplicados para o Brasil. E aqueles que estudam apresentam finalidades distintas e não consideram a heterogeneidade de spin-offs da mesma forma.

Ribeiro et al. (2017) leva em conta a heterogeneidade de spin-offs, replicando Benedetto et al. (2007), mas não analisa a performance das diferentes firmas entrantes. Muendler et al. (2012) chega a comparar a taxa de sobrevivência das spin-offs com a de outras firmas entrantes, porém não analisa como elas crescem. Sarada e Tocoian (2018), por outro lado, abordam a sobrevivência e crescimento, mas não segmentam as spin-offs em pulled e pushed spin-offs.

Além disso, os trabalhos que analisam para outros países a performance de spin-off de empregados parecem não convergir em dois aspectos. Primeiro, com relação à taxa de crescimento de spin-offs e nãospin-offs. Enquanto alguns autores verificam que spin-offs experimentam no curto prazo taxa de crescimento superior à taxa das demais firmas entrantes (ANDERSSON e KEPPLER, 2013; FRYGES et al., 2014), Sarada e Tocoian (2018) afirmam que novas firmas com empregados previamente conectados - proxy para spin-off de empregados - apresentam, porém, menor taxa de crescimento no curto prazo. Apesar de concordarem quanto ao indicador de sobrevivência.

Segundo, a visão de que pulled spin-off possui performance superior à pushed spin-off não é compartilhada por toda a literatura. Enquanto uma parte da literatura encontra evidências da superioridade de pulled spin-offs (ERIKSSON e KUHN, 2006; ANDERSSON e KLEPPER, 2013; FACKLER et al., 2016), Rocha (2014a, 2014b) conclui que não considera esse resultado estatisticamente significativo.

\section{DADOS E METODOLOGIA}

O Instituto de Economia da UFRJ, através do PDES do MTE disponibiliza o acesso a pesquisadores internos, de forma controlada e sob condições de sigilo e responsabilidade para uso apenas estatístico dos dados, a RAIS Empregado, fonte de dados para este trabalho. A Relação Anual de Informações Sociais - RAIS (Ministério da Economia) é considerado um censo do mercado de trabalho formal $^{9}$, onde as firmas são obrigadas a declarar anualmente informações referentes a cada um de seus empregados.

Por se tratar de uma base dados que relaciona de maneira unívoca firmas e empregados, ela permite a categorização de firmas através do fluxo de empregados entre as firmas, adequando-se perfeitamente à técnica proposta por Benedetto (2007).

A RAIS Trabalhador contém informações relativas a diversas características das firmas e seus empregados. Para as firmas tem-se o identificador (CNPJ com 12 dígitos); natureza jurídica, que estabelece a forma legal da firma e permite identificar caso se trata de administração pública, entidade empresarial, entidade sem fins lucrativos ou pessoa física; e atividade econômica através da Classificação Nacional de Atividade Econômica - CNAE à 5 dígitos. Cada uma dessas firmas, informa à RAIS inúmeras características de seus empregadores, dentre elas o identificador do empregado através do código PIS (Programa de Integração Social), as datas de início e fim do vínculo empregatício, nível de escolaridade, idade, sexo, cargo e salário.

Este capítulo tem por finalidade estabelecer definições básicas para utilização e tratamento dos microdados da RAIS, como o âmbito das firmas entrantes e o período de análise, bem os critérios para identificação dos spin-offs e de empresas gazelas.

\subsection{MICRODADOS DA RAIS}

Firmas entrantes excluídas. Serão desconsideradas as formais legais de administração pública, entidade sem fins lucrativos e pessoa física. Em linha com Sarada e Tocoian (2018), o foco será no

\footnotetext{
${ }^{9}$ Os trabalhadores informais como, por exemplo, autônomos, familiares sem remuneração e quem não possui carteira assinada não são cobertos pela RAIS. O total de trabalhadores informais em 2017 representa 40,8\% de toda a população ocupada no país, de acordo com dados da PNAD Contínua do IBGE.
} 
conjunto das entidades empresariais, com algumas exceções ${ }^{10}$ : empresas domiciliadas no exterior; aquelas com propriedades estatal; empresário individual, por contemplar muitos MEI's que geralmente não são obrigados a declarar RAIS ${ }^{11}$; cooperativas; e consórcios, já que não há criação de novo negócio, apenas de um ente jurídico que representa um conjunto de firmas ou empregados, sem contar que podem ser criadas com finalidade específica e tempo determinado.

Quanto ao tamanho permitido da nova firma, serão consideradas apenas firmas com no mínimo 5 e no máximo 100 empregados, em linha, respectivamente, com Muendler et al. (2012) e Sarada e Tocoian (2018).

Critério de entrada e saída de firma ${ }^{\mathbf{1 2}}$. São consideradas como empresas novas no ano $t$, aquelas que não tenham declarado RAIS nos dois anos anteriores ( $t$ e $t$ - $l$ ) ou possua zero pessoal ocupado assalariado em 31 de dezembro do mesmo período.

Para o critério de saída, adota-se uma regra ainda mais simples. Se a firma não tiver declarado a RAIS em determinado ano $(t)$ ou não possuir pessoal ocupado assalariado, considera-se que ela saiu (ou não é sobrevivente) no ano $t$.

Período de análise. Em 2006 houve reestruturação da CNAE da versão 1.0 para 2.0, o que dificulta uma comparação setorial com período anterior. O período mais recente que temos é o ano de 2015. Desse modo, o estudo das firmas entrantes será realizado do período de 2006 a 2015. Para a análise de sobrevivência e crescimento, quando se observa a firma em $t+3$ e $t+6$, os períodos se restringirão, respectivamente, de 2006 a 2012 e de 2006 a 2009.

\subsection{CRITERIOS PARA IDENTIFICAÇÃO DE SPIN-OFF}

Como apresentado no capítulo anterior, parte dos trabalhos sobre spin-off de empregados seguem, em linhas gerais, um critério parecido de fluxo de empregados. O que muda são os pontos de corte e o número mínimo de empregados. Neste sentido, nos basearemos em Muendler et al. (2012), que considera um mínimo de 5 empregados e um corte de $25 \%^{13}$. Ou seja, se $25 \%$ ou mais dos empregados da firma entrante vierem de uma mesma firma antecessora (firma pai), então será identificada como spin-off.

Uma vez identificado os spin-offs, eles podem ser do tipo pulled e pushed. Seguindo a maioria da literatura, caso a firma pai sobreviva no ano de criação da spin-off, será categorizada como pulled spinoff. Caso contrário, a firma pai não sobreviva, será identificada como pushed spin-off. Os restantes das firmas entrantes serão chamados de 'demais entrantes'.

Vejamos um exemplo da identificação. Considere a firma A no ano $t$ - 1 . Suponha que 5 empregados da firma A saiam em conjunto uma nova firma $\mathrm{B}$ e que em t esta firma possua 10 empregados. Suponha ainda que A continua em operação. Como 5, atende aos limites (mínimo e máximo) e representa $50 \%$ do total de empregados da firma entrante, portanto, superior a $25 \%$, tem-se que B é um pulled spin-off. Caso A tivesse encerrado as atividades em $t$, B seria pushed spin-off.

O uso do simples ponto de corte não impede que o spin-off possa ter mais de uma firma pai. Neste caso, será priorizada aquela que forneceu mais empregados ao spin-off. Em caso de empate, prevalecerá aquela com maior número de empregados no ano anterior do surgimento do spin-off.

\footnotetext{
${ }^{10}$ Códigos 221-6 (empresa domiciliada no exterior), 201-1 (empresa pública), 203-8 (sociedade de economia mista), 213-5 (empresário individual), cooperativas (214-3 e 233-3), consórcios (215-1, 216-0, 228-3, 229-1).

11 Isto pode gerar problemas na identificação de entrada e saída de firmas, bem como no cálculo de crescimento de empregados. Sem contar que, por definição, não se espera que o foco da empresa seja crescimento.

${ }^{12}$ A identificação de firmas novas ou que estão saindo do mercado passa por uma avaliação que não depende apenas de um simples indicador. Mesmo que houvesse nos microdados da RAIS Empregado a informação do ano de fundação da firma, variável que reconhecidamente apresentada limitações, há a intermitência na declaração da RAIS.

${ }^{13}$ Ao contrário de, por exemplo, Eriksson e Kuhn (2006) e Andersson e Klepper (2013) que usam 50\% de corte e um mínimo de dois e máximo de 10 empregados. Mesmo assim, apesar dessas diferenças, Eriksson e Kuhn (2006) aponta que, ao replicar os testes com um percentual de corte reduzido para 30\%, os resultados não necessariamente se alteram qualitativamente.
} 


\subsection{CRITÉRIO PARA IDENTIFICAÇÃO DE GAZELAS}

De acordo com o guia da UNECE $(2018)^{14}$, e utilizado pelos países da OCDE, sobre uso de registros administrativos para estatísticas de demografia de empresas e empreendedorismo, gazelas são empresas de alto crescimento (EAC) com poucos anos de idade. Sendo EAC aquelas com pelo menos 10 empregados no ano inicial de observação e que por um período de 3 anos apresenta um crescimento médio de empregados maior do que $10 \%$ ao ano. Já as gazelas são as EAC desde que possuam até 5 anos de idade no ano de referência, portanto, empresas relativamente recém-criadas.

Cabe mencionar que neste conceito, como se considera o crescimento médio em um horizonte de três anos, pode ocorrer em determinado ano de a firma não ter crescimento ou até ter crescimento negativo. Porém, desde que ela tenha um crescimento acumulado de $33,1 \%$ no período, o que equivale a $10 \%$ ao ano, a empresa será identificada de alto crescimento.

Para este trabalho seguiremos a definição recomendada pela Comissão Européia, com uma diferença. As empresas entrantes possuem um porte mínimo de 5 empregados. Por outro lado, o porte mínimo das EAC é de 10 empregados. Para que não deixemos de fora as firmas com 5 a 9 empregados, elas são incluídas no nosso conceito de alto crescimento e, consequentemente, no conceito de gazela.

\section{ANALISE DESCRITIVA}

Evolução da entrada de firmas, segundo os tipos de spin-off e demais entrantes. A Tabela 4.1 descreve a formação de empresas, segundo os tipos de spin-off, de 2006 a 2015 . A representatividade de spin-offs no total de empresas entrantes oscilou entre 14,2\% a 19,8\%, com tendência de crescimento nos últimos e com aparente maior formação relativa nos anos em que houve menor atividade econômica. Eriksson e Kuhn (2006, p. 1023) também observam comportamento semelhante. Os autores observam que em períodos de recessão há um aumento na formação de spin-offs e sugerem que elas são influenciadas mais pela necessidade (pushed) do que pela oportunidade (pulled).

Tabela 4.1 - Evolução anual das firmas entrantes de 2006 a 2015, segundo spin-offs, seus tipos, e demais entrantes.

\begin{tabular}{l|c|c|c|c|c|c|c|c|c|c}
\hline Firmas entrantes & $\mathbf{2 0 0 6}$ & $\mathbf{2 0 0 7}$ & $\mathbf{2 0 0 8}$ & $\mathbf{2 0 0 9}$ & $\mathbf{2 0 1 0}$ & $\mathbf{2 0 1 1}$ & $\mathbf{2 0 1 2}$ & $\mathbf{2 0 1 3}$ & $\mathbf{2 0 1 4}$ & $\mathbf{2 0 1 5}$ \\
\hline Total de entrantes & $\mathbf{3 3 . 7 4 3}$ & $\mathbf{3 7 . 0 8 2}$ & $\mathbf{4 2 . 5 2 9}$ & $\mathbf{4 4 . 7 5 3}$ & $\mathbf{4 7 . 9 7 2}$ & $\mathbf{5 1 . 1 8 9}$ & $\mathbf{5 5 . 1 5 8}$ & $\mathbf{4 7 . 6 0 3}$ & $\mathbf{4 3 . 2 1 5}$ & $\mathbf{4 1 . 5 9 5}$ \\
\hline Spinoffs & $15,0 \%$ & $15,7 \%$ & $15,1 \%$ & $16,7 \%$ & $14,8 \%$ & $16,1 \%$ & $14,2 \%$ & $16,6 \%$ & $16,7 \%$ & $19,8 \%$ \\
\hline Pulled & $10,2 \%$ & $10,6 \%$ & $10,2 \%$ & $10,8 \%$ & $10,2 \%$ & $11,3 \%$ & $9,9 \%$ & $11,2 \%$ & $11,6 \%$ & $13,0 \%$ \\
\hline Pushed & $4,8 \%$ & $5,2 \%$ & $4,9 \%$ & $5,9 \%$ & $4,6 \%$ & $4,8 \%$ & $4,3 \%$ & $5,3 \%$ & $5,0 \%$ & $6,7 \%$ \\
\hline Demais entrantes & $85,0 \%$ & $84,3 \%$ & $84,9 \%$ & $83,3 \%$ & $85,2 \%$ & $83,9 \%$ & $85,8 \%$ & $83,4 \%$ & $83,3 \%$ & $80,2 \%$ \\
\hline \hline Var. PIB nominal $(\%)$ & $4,0 \%$ & $6,1 \%$ & $5,1 \%$ & $-0,1 \%$ & $7,5 \%$ & $4,0 \%$ & $1,9 \%$ & $3,0 \%$ & $0,5 \%$ & $-3,5 \%$ \\
\hline
\end{tabular}

Fonte: Elaboração própria a partir dos dados da RAIS Empregado 2004-2015.

Os dados para o Brasil parecem reforçar essa relação entre ciclos econômicos e formação de spinoff. Uma análise da correlação linear de Pearson entre a proporção de spin-offs e o crescimento do PIB mostra uma relação negativa, no valor de $-0,77$. Ainda, observa-se que nos períodos de recessão (2009 e 2015) houve uma maior contribuição de pushed spin-off.

Spin-offs são majoritariamente do tipo pulled, comportamento em linha com o de outros países. Enquanto no Brasil o número de pulled spin-off é o dobro do número de pushed spin-off, na Dinamarca e Suécia essa relação é cerca do triplo, apesar das diferenças metodológicas.

Perfil dos empregados de spin-offs entrantes. A Tabela 4.2 apresenta um resumo das dotações iniciais de capital humano dessas firmas, bem como indicadores e relacionamento prévio entre os empregados. Através da tabela é possível ter uma percepção de qual é a experiência profissional dos

\footnotetext{
${ }^{14}$ Em linha com a Regulação no 439/2014 da Comissão Europeia.
} 
empregados (a partir da proxy por idade e a proporção daqueles que estão no primeiro emprego), o nível de escolaridade, a composição por gênero e a produtividade do fator trabalho (a partir de proxy do salário médio). Embora se tenha informação até o ano de 2015, optou-se pelo recorte de 2006 a 2012, por ser o período em que é possível obter taxas de sobrevivência e de crescimento.

Verifica-se que os spin-offs entrantes no Brasil, em relação às demais empresas entrantes, são formados por empregados mais experientes, com perfil mais próximo às firmas existentes. Eles possuem uma maior média de idade (32,8 contra 31,5 anos dos demais entrantes) e absorvem proporcionalmente menos mão de obra que está iniciando seu primeiro emprego (6,6\% contra 14,0\%). Além disso, uma proporção superior de seus empregados apresenta maior nível de escolaridade $(9,6 \%$ contra $5,3 \%)$ e recebe uma remuneração média mais elevada $(\mathrm{R} \$ 1.760$ contra $\mathrm{R} \$ 1.255)$

Tabela 4.2 - Perfil dos empregados de spin-offs entrantes de 2006 a 2012, segundo dotações iniciais de capital humano.

\begin{tabular}{|c|c|c|c|c|c|}
\hline \multirow{2}{*}{ Variáveis } & \multicolumn{3}{|c|}{ Spinoffs entrantes } & \multirow{2}{*}{$\begin{array}{c}\text { Demais } \\
\text { entrantes }\end{array}$} & \multirow{2}{*}{$\begin{array}{c}\text { Firmas } \\
\text { existentes (4) }\end{array}$} \\
\hline & Total & Pulled & Pushed & & \\
\hline Idade média (anos) & 32,8 & 32,8 & 32,9 & 31,5 & 33,5 \\
\hline Mais es colarizados (\%) (1) & $9,6 \%$ & $9,9 \%$ & $8,8 \%$ & $5,3 \%$ & $9,3 \%$ \\
\hline Homens $(\%)$ & $62,9 \%$ & $65,0 \%$ & $58,4 \%$ & $60,6 \%$ & $65,7 \%$ \\
\hline Primeiro emprego $(\%)$ & $6,6 \%$ & $6,4 \%$ & $6,9 \%$ & $14,0 \%$ & $5,7 \%$ \\
\hline Salário médio real (R\$) (2) & 1.760 & 1.865 & 1.538 & 1.255 & 1.967 \\
\hline HHI (3) & 0,254 & 0,242 & 0,281 & - & - \\
\hline
\end{tabular}

Fonte: Elaboração própria a partir dos dados da RAIS Empregado 2004-2012.

Notas: Os valores de média utilizam média aritmética dentro de cada grupo. (1) Empregados com nível superior completo. (2) Salários inflacionados para 2015 pelo Índice Nacional de Preços ao Consumidor - INPC. (3) Ver conceito da versão normalizada do HHI (Herfindahl Hirschman Index) proposto por Sarada e Tocoian (2018) no Quadro 5.1. (4) Para fins de melhor comparabilidade com as empresas entrantes, foram consideradas apenas empresas com 5 empregados ou mais.

Também há diferenças entre o perfil de empregados por tipos de spin-offs. Pulled spin-off apresentam, em relação à pushed spin-off, mais empregados do sexo masculino, com menor escolaridade e menor remuneração média. A idade média, porém, é idêntica entre os tipos de spin-off. Pushed spin-off contratam relativamente mais empregados que iniciam o primeiro emprego (6,9\% contra 6,4\%).

Replicou-se o HHI proposto por Sarada e Tocoian (2018). Este indicador pode ser interpretado como um grau de conexão prévia entre os empregados do spin-off, em que 0 (zero) não há vinculo prévio e 1 representa que todos os empregados do spin-off vieram de um mesmo empregador anterior. Observase que o grau de conexões entre pushed spin-off é superior ao pulled.

Distribuição setorial. A Tabela 4.3 mostra por setor, ao nível de 1 dígito CNAE, a distribuição de spin-offs, demais empresas entrantes e firmas existentes. Grosso modo, a proporção de abertura de firma nos setores segue a distribuição das firmas já estabelecidas no mercado. As atividades de comércio e serviços concentram grande parte das firmas, com mais de $65 \%$ das empresas, seguidas pelo setor da indústria. Ocorre, porém, desvios interessantes que podem ilustrar algumas características dos spin-offs.

Primeiro, formaram-se relativamente menos spin-offs no setor de Construção, 9,7\% contra 12,3\% dos demais entrantes, especialmente devido aos pushed spin-offs. Vale lembrar que período de 2006 a 2012 foi marcado por uma significativa expansão do setor ${ }^{15}$. Essa forte evolução fez com que menos empresas pai - que gerariam os spin-off - saíssem do mercado no mesmo ano em que os spin-offs foram gerados. Ao contrário do setor de Comércio, onde o número de empresas cresceu apenas $8 \%$

\footnotetext{
15 Segundo dados do Cadastro Central de Empresas (2014), enquanto o número total de empresas no país cresceu $21 \%$, o número de empresas no setor de Construção cresceu $98 \%$.
} 
(CADASTRO ..., 2016). Este comportamento contribui para a formação de um menor número relativa de spin-offs que buscavam oportunidades (30,9\%) e mais spin-off que surgiram por necessidade $(38,3 \%)$.

Segundo, a maior concentração de spin-offs é no setor de serviços. O racional utilizado, com base no ciclo econômico, para explicar a alta concentração no setor de Comércio e menor concentração no setor de Construção (em relação aos demais entrantes) parece não se explicar o comportamento do setor de serviços ${ }^{16}$. A hipótese mais razoável é a tendência geral de terceirização das atividades ou da desverticalização das empresas. Uma análise mais desagregada das atividades dentro do setor de serviços, que é bastante heterogêneo, é possível relacionar spin-offs mais voltados para atividades meio e spin-off mais voltados para atividade fim. Além disso, verificar como spin-off de empregados escolhem atividades que envolvem conhecimento específicos e que, neste nível de desagregação, parece valer a ideia da maior penetração de spin-offs.

Tabela 4.3 - Distribuição das empresas entrantes de 2006 a 2012 e percentual de spin-off com mesma CNAE da firma pai, segundo setores e tipos de entrantes.

\begin{tabular}{|c|c|c|c|c|c|c|}
\hline \multirow{3}{*}{$\begin{array}{c}\text { Setor de atividade } \\
\text { (CNAE } 1 \text { dígito - Seção) }\end{array}$} & \multirow{2}{*}{\multicolumn{3}{|c|}{ Spin-offs entrantes }} & \multirow{3}{*}{$\begin{array}{c}\text { Demais } \\
\text { entrantes }\end{array}$} & \multirow{3}{*}{$\begin{array}{c}\text { Firmas } \\
\text { existentes (1) }\end{array}$} & \multirow{3}{*}{$\begin{array}{l}\text { \% Spin-off entrantes } \\
\text { com mesma CNAE (2 } \\
\text { díg.) da firma pai (2) }\end{array}$} \\
\hline & & & & & & \\
\hline & Total & Pulled & Pushed & & & \\
\hline Agricultura, Pecuária (A) & $1,2 \%$ & $1,3 \%$ & $1,0 \%$ & $1,3 \%$ & $1,1 \%$ & $48,1 \%$ \\
\hline Indú stria $(\mathrm{B}, \mathrm{C}, \mathrm{D}, \mathrm{E})$ & $17,1 \%$ & $17,9 \%$ & $15,4 \%$ & $15,8 \%$ & $20,1 \%$ & $60,8 \%$ \\
\hline Constru ção (F) & $9,7 \%$ & $11,3 \%$ & $6,2 \%$ & $12,3 \%$ & $5,3 \%$ & $56,3 \%$ \\
\hline Comércio (G) & $33,8 \%$ & $31,5 \%$ & $38,8 \%$ & $35,5 \%$ & $40,0 \%$ & $70,9 \%$ \\
\hline Serviços (H a N, R, S) & $34,1 \%$ & $34,1 \%$ & $34,1 \%$ & $30,8 \%$ & $27,0 \%$ & $45,9 \%$ \\
\hline Edu cação (P) & $2,9 \%$ & $2,7 \%$ & $3,4 \%$ & $3,1 \%$ & $3,8 \%$ & $82,9 \%$ \\
\hline Saúde (Q) & $1,2 \%$ & $1,2 \%$ & $1,1 \%$ & $1,2 \%$ & $2,6 \%$ & $76,1 \%$ \\
\hline Total & $100,0 \%$ & $100,0 \%$ & $100,0 \%$ & $100,0 \%$ & $100,0 \%$ & $59,3 \%$ \\
\hline
\end{tabular}

Fonte: Elaboração própria a partir dos dados da RAIS Empregado 2004-2012.

Notas: (1) Para fins de melhor comparabilidade com as empresas entrantes, foram consideradas apenas empresas com 5 empregados ou mais. (2) Dados referentes ao período de 2007 a 2012, pois as firmas pai dos spin-offs de 2006 possuem CNAE 1.0 , versão anterior à 2.0 em uso neste trabalho.

A Tabela 4.3 também apresenta o percentual de spin-offs que entraram no mercado com a mesma atividade (CNAE 2 dígitos) da firma pai. Do total de spin-offs entrantes, 59,3\% mantiveram-se na CNAE da firma pai. Este percentual varia consideravelmente entre os setores. E, uma visão semelhante da mesma tabela, mas ao nível de 1 dígitos de CNAE e sem os agrupamentos de atividade mostra que o setor com maior percentual de spin-offs com a mesma CNAE da firma pai não necessariamente significa uma penetração maior de spin-off neste setor respectivo. O que contraria a hipótese de que quanto maior o conhecimento específico sobre o setor, menor a barreira a entrada e maior a penetração de spin-offs.

Comparativo de performance entre novas empresas. A seguir, estuda-se o sucesso das novas firmas em termos de sobrevivência e crescimento, mantendo o objetivo de endereçar três dos principais objetivos: como spin-off performam em relação aos demais entrantes; se no Brasil pulled spin-off performa melhor do que pushed spin-off; e se o fato de a empresa nascer de um spin-off aumenta a probabilidade de se tornar gazela.

A Tabela 4.4 apresenta um resumo, sem o controles de heterogeneidade, das taxas de sobrevivência e de crescimento, após dois períodos, que chamaremos de curto prazo (3 anos) e médio prazo (6 anos). São apresentados dois indicadores de crescimento. O primeiro mostra uma taxa de

\footnotetext{
${ }^{16}$ Da mesma forma que na Construção, o setor de Serviços apresentou no período um crescimento superior ao crescimento do número total de empresas ( $46 \%$ contra $21 \%$ do total). Apesar de ter sido bastante superior, e que na lógica do crescimento econômica (ERIKSSON e KUHN, 2006) induziria a uma menor formação de spin-off no setor de serviços, não é o que se observa.
} 
crescimento simples que considera apenas o número de empregados no ano inicial e final de observação $t x=\frac{E_{t+n}-E_{t}}{E_{t}}$ (eq. 1), onde $n=3$ se $2006 \leq t \leq 2012$ e $n=6$ se $2006 \leq t \leq 2009$. O segundo indicador segue em linha com o importante estudo de Davis e Haltiwanger (1992): $t x=\frac{E_{t+n}-E_{t}}{0.5\left(E_{t}+E_{t+n}\right)}$ (eq. 2). Eles apontam para a necessidade de se considerar no denominador o tamanho médio da empresa, entre o ano inicial e final de observação, em prol de reduzir os efeitos de regressão a média e evitar viés.

Além disso, tem-se a proporção de entrantes que se tornaram gazelas, que não apenas serve como forma complementar de mensurar o crescimento dos entrantes, como também pode dar uma pista se este importante grupo de empresas, destacadas por contribuírem para o crescimento econômico e por gerarem relativamente muitos empregos (HENREKSON e JOHANSSON, 2010; SENDEROVITZ et al., 2012), tem maior probabilidade de se tornarem gazelas ou representam a maior parte destas.

Tabela 4.4 - Taxa de sobrevivência e crescimento de empregados, segundo tipos de firmas entrantes de 2006 a 2012.

\begin{tabular}{|c|c|c|c|c|c|c|c|}
\hline \multirow{2}{*}{\multicolumn{2}{|c|}{ Indicador de desempenho }} & \multirow{2}{*}{ Período } & \multicolumn{3}{|c|}{ Spin-off entrante } & \multirow{2}{*}{$\begin{array}{c}\text { Demais } \\
\text { entrantes }\end{array}$} & \multirow{2}{*}{$\begin{array}{c}\text { Total dos } \\
\text { entrantes }\end{array}$} \\
\hline & & & Total & Pulled & Pushed & & \\
\hline \multicolumn{2}{|c|}{ Proporção de empresas sobreviventes } & $\begin{array}{l}\mathrm{t} \text { a } t+3 \\
\mathrm{t} \text { a } t+6 \\
\end{array}$ & $\begin{array}{l}77,2 \% \\
62,3 \% \\
\end{array}$ & $\begin{array}{l}77,6 \% \\
62,9 \% \\
\end{array}$ & $\begin{array}{l}76,5 \% \\
61,3 \% \\
\end{array}$ & $\begin{array}{l}68,4 \% \\
53,3 \% \\
\end{array}$ & $\begin{array}{l}69,8 \% \\
54,7 \% \\
\end{array}$ \\
\hline \multirow{2}{*}{$\begin{array}{r}\text { Taxa de } \\
\text { crescimento de } \\
\text { empregados }\end{array}$} & \multirow{2}{*}{$\begin{array}{c}t x=\frac{E_{t+n}-E_{t}}{E_{t}} \\
t x=\frac{E_{t+n}-E_{t}}{0.5\left(E_{t}+E_{t+n}\right)}\end{array}$} & $\begin{array}{l}\mathrm{t} \text { a } t+3 \\
\mathrm{t} a \mathrm{t}+6\end{array}$ & $\begin{array}{l}61,0 \% \\
97,1 \%\end{array}$ & $\begin{array}{c}73,3 \% \\
116,3 \%\end{array}$ & $\begin{array}{l}31,0 \% \\
51,8 \%\end{array}$ & $\begin{array}{l}51,6 \% \\
90,5 \%\end{array}$ & $\begin{array}{l}53,7 \% \\
92,0 \%\end{array}$ \\
\hline & & $\begin{array}{l}\mathrm{t} \text { a } \mathrm{t}+3 \\
\mathrm{t} \text { a } \mathrm{t}+6\end{array}$ & $\begin{array}{l}23,4 \% \\
32,7 \% \\
\end{array}$ & $\begin{array}{l}26,8 \% \\
36,8 \% \\
\end{array}$ & $\begin{array}{l}13,4 \% \\
20,6 \% \\
\end{array}$ & $\begin{array}{l}20,5 \% \\
31,2 \% \\
\end{array}$ & $\begin{array}{l}21,2 \% \\
31,5 \% \\
\end{array}$ \\
\hline \multicolumn{2}{|c|}{ Proporção de empresas gazelas } & $\mathrm{tat}+3$ & $32,3 \%$ & $35,3 \%$ & $25,7 \%$ & $27,2 \%$ & $28,0 \%$ \\
\hline
\end{tabular}

Fonte: Elaboração própria a partir dos dados da RAIS Empregado 2004-2015.

Nota: Nos períodos em $\mathrm{t}+3$ e $\mathrm{t}+6$ são consideradas as empresas que entraram nos anos de, respectivamente, 2006 a 2012 e 2006 a 2009. (1) Taxa de crescimento de empregados $=\mathrm{N}^{\mathrm{o}}$ empregado $_{t+\mathrm{n}} / \mathrm{N}^{\mathrm{o}}$ empregados $_{\mathrm{t}}$. (2) Taxa de crescimento de

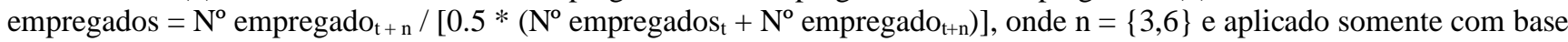
nas firmas sobreviventes.

Primeiramente, nota-se que spin-offs possuem taxas de sobrevivência maiores do que a taxa dos demais entrantes, tanto no curto quanto no médio prazo, havendo pouca diferença entre pulled e pushed spin-offs. Em contrapartida, o mesmo comportamento não ocorre na taxa de crescimento. Na média, spinoffs continuam com taxa de crescimento superior à taxa dos demais entrantes. Entretanto, há uma diferença relevante entre os tipos de spin-offs, com pushed spin-offs apresentando cerca de menos da metade da taxa de crescimento dos pulled spin-offs. A menor diferença entre esses tipos é encontrada quando se compara um horizonte de médio prazo cuja base de referência seja o tamanho médio da empresa ${ }^{17}$.

Quando se analisa a proporção de empresas entrantes no ano $t$ e que se tornaram gazelas em $t+3$, observa-se um comportamento muito semelhante à taxa de crescimento no curto prazo. Uma proporção maior de spin-off entrante se torna gazela em relação aos demais entrantes. Além disso, continua havendo uma diferença entre os tipos de spin-offs, porém menos importante.

Outras variáveis ao nível da firma. Por fim, cabe destacar duas variáveis que afetam o desenvolvimento o crescimento das firmas: porte e indicador de SIMPLES, cujas motivações são explicadas no capítulo seguinte. Em se tratando de estudo a respeito de sobrevivência e crescimento de firmas, conhecer seu porte na entrada e outras características ao nível da firma é fundamental.

\footnotetext{
${ }^{17}$ A replicação da Tabela 4.5 com percentuais de cortes aumentados alteram qualitativamente os resultados, ao contrário de Eriksson e Kuhn (2006). O uso do ponto de corte de 50\% resulta em maior proporção de sobreviventes e a menor taxa de crescimento para todos os tipos de entrantes. Contudo, a taxa de crescimento de spin-offs no curto prazo $(47,9 \%)$ é inferior à taxa das demais entrantes $(54,3 \%)$. A adoção de ponto de corte de $80 \%$ mantém qualitativamente o resultado do corte de $25 \%$.
} 
A Tabela 4.5 apresenta, por tipo de entrante, o número médio de empregados das empresas e a proporção de firmas que adotaram o regime tributário SIMPLES Nacional, elegível para micro e pequenas empresas com faturamento de até $\mathrm{R} \$ 3,6$ milhões.

A análise do porte médio mostra que os spin-offs possuem aproximadamente $40 \%$ a mais do tamanho dos que os demais entrantes, sendo que pulled tem tamanho superior ao pushed spin-off.

Quanto à escolha pelo regime de tributação, spin-offs aderem menos ao Simples Nacional. Enquanto $64,8 \%$ das demais entrantes optam pelo SIMPLES, 56,5\% dos spin-offs fazem a mesma escolha. Pushed spin-off apresentam percentual próximo aos dos demais entrantes. Os dados sugerem uma correlação negativa entre porte e escolha pelo SIMPLES.

Tabela 4.5 - Porte médio e proporção de empresas que adotaram o SIMPLES de 2006 a 2012, segundo spin-offs, seus tipos, e demais entrantes.

\begin{tabular}{|c|c|c|c|c}
\hline \multirow{2}{*}{ Características ao nível das empresas } & \multicolumn{2}{|c|}{ Spin-offs entrantes } & \multirow{2}{*}{$\begin{array}{c}\text { Demais } \\
\text { entrantes }\end{array}$} \\
\cline { 2 - 4 } & Total & Pulled & Pushed & \\
\hline Porte (em número médio de empregados) (1) & 16,1 & 16,7 & 14,9 & 12,0 \\
\hline Proporção de empresas que optaram pelo SIMPLES tributário & $56,5 \%$ & $53,9 \%$ & $62,2 \%$ & $64,8 \%$ \\
\hline
\end{tabular}

Fonte: Elaboração própria a partir dos dados da RAIS Empregado 2004-2012.

Nota: (1) São consideradas para análise apenas empresas com porte de no mínimo 5 empregados e máximo de 100 empregados.

\section{ESTRATÉGIA EMPÍRICA}

A análise empírica tem por finalidade estudar para a sobrevivência, para o crescimento e para as gazelas o efeito das dotações iniciais de capital humano, da intensidade da conexão prévia entre os empregados, das características ao nível das firmas (spin-offs e sua firma pai) e de características ao nível setorial. Além disso, testar a hipótese que pulled performam melhor do que pushed spin-off.

Para este propósito, são analisados 10 modelos, divididos em dois grupos. Os cinco primeiros consideram os três tipos de entrantes (pulled spin-off, pushed spin-off e demais entrantes, sendo este a categoria omitida). Os cinco últimos consideram somente os tipos de pulled spin-off e pushed (categoria omitida). Porém, estes incorporam variáveis referentes a conexão prévia entre empregados e características sobre a firma pai, exclusivas aos spin-offs. Além disso, exceto para a regressão das gazelas $^{18}$, são aplicados modelos para $t=3$ (curto prazo) e $t=6$ (médio prazo).

Controles e variáveis explicativas. Os anos em que as firmas entram no mercado, bem como o setor em que iniciam suas atividades são controlados por efeitos fixos. Em virtude deste controle, características ao nível setorial seriam redundantes.

Em todos os modelos as variáveis explicativas são agrupadas de acordo com dotações de capital humano dos empregados no ano de entrada da empresa (idade média em anos, share dos mais escolarizados, share de homens, share de primeiro emprego e média salarial em log) e características ao nível das firmas (dummy de demais entrantes, dummy de pulled spin-off e de pushed spin-off, dummy de simples tributário e porte da firma entrante em log de número de empregados).

Exclusivamente para o segundo grupo de modelos, que analisa apenas pulled spin-off e pushed spin-off, além das variáveis recém-citadas, também se considera mais duas características ao nível da firma (dummy de spin-off no mesmo setor da firma pai e porte da firma pai em log de número de empregados) e uma variável de relacionamento prévio entre os empregados (através do HHI). Uma descrição completa das variáveis pode ser encontrada no Quadro 5.1.

\footnotetext{
${ }^{18}$ As gazelas, por definição, possuem até 5 anos de idade. O uso do período t+6, ou seja, 6 anos após o nascimento da firma faria com que a firma entrante não atendesse o critério de gazela.
} 
O uso de variáveis de capital humano se faz importante pela necessidade de controlar pelos a abertura da firma pelos distintos perfis empregados fundadores, de modo que seja possível comparar firmas com semelhantes dotações iniciais de capital humano, por exemplo, firmas entrantes com mesmo grau de escolaridade, ceteris paribus.

Analogamente, a utilização de variáveis relacionadas a características ao nível da firma é importante. Os determinantes de sobrevivência e crescimento de firmas geralmente estão relacionados e, por consequência, suas respectivas taxas. Porém, não parece ser o caso entre os tipos de spin-offs. Apesar de pulled e pushed spin-off terem taxas semelhantes de sobrevivência, o mesmo não ocorre com suas taxas de crescimento. Das informações que temos disponíveis para fins de controles e que podem contribuir na explicação desse fenômeno, três delas merecem destaque.

Quadro 5.1 - Variáveis consideradas para análise das firmas entrantes.

\begin{tabular}{|c|c|}
\hline \multicolumn{2}{|c|}{ Dotação inicial de capital humano dos empregados } \\
\hline Idade média (anos) & Idade média dos empregados, por firma, na entrada \\
\hline $\begin{array}{l}\text { Share dos mais escolarizados } \\
(\%)\end{array}$ & $\begin{array}{l}\text { Proporção dos empregados que possuem nível superior em relação ao total de } \\
\text { empregados, por firma, na entrada }\end{array}$ \\
\hline Share de homens $(\%)$ & $\begin{array}{l}\text { Proporção dos empregados homens em relação ao total de empregados, por firma, na } \\
\text { entrada }\end{array}$ \\
\hline Share de primeiro emprego $(\%)$ & Proporção de empregados que estão assinando carteira de trabalho pela primeira vez \\
\hline Média salarial (log) & $\begin{array}{l}\text { Média salarial dos empregados em termo reais (deflacionado pelo INPC), por firma, na } \\
\text { entrada. }\end{array}$ \\
\hline \multicolumn{2}{|c|}{ Medida de relacionamento prévio entre empregados } \\
\hline HHI de empregados & $\begin{array}{l}\text { Proposto por Sarada e Tocoian (2018), a variável mensura o quão "concentrado" } \\
\text { empregados com relações profissionais anteriores estão dentro de pool de empregados } \\
\text { da nova firma. } 0 \text { (zero) indica que não há qualquer relação prévia entre os empregados } \\
\text { da nova firma, e } 1 \text { onde todos os empregados da nova firma trabalharam juntos no } \\
\text { mesmo empregador anterior. Se o spin-off tem } \mathrm{N} \text { empregados, e tais empregados tem } \\
\text { um total de J empregadores prévios, cada representado na nova firma por } \mathrm{N}_{\mathrm{j}} \\
\text { trabalhadores, então o indicador HHI de concentração prévio de empregadores é dado } \\
\text { por } H H I=\sum_{j=1}^{J} \frac{N_{j}\left(N_{j}-1\right)}{N(N-1)} \text { para } \mathrm{N} \geq 5\end{array}$ \\
\hline \multicolumn{2}{|c|}{ Características iniciais ao nível das firmas } \\
\hline Tipos de firmas entrantes & Indicação se a firma é do tipo pulled spin-off, pushed spin-off ou demais entrantes. \\
\hline Indicador de SIMPLES tributário & Indicador de que a empresa adere ao regime tributário do SIMPLES. \\
\hline $\begin{array}{l}\text { Mesmo setor da firma pai } \\
(\text { dummy) }\end{array}$ & $\begin{array}{l}\text { Variável dummy igual a } 1 \text { indicando se spin-off iniciou a operar na mesma CNAE ( } 2 \\
\text { dígitos) da firma pai, } 0 \text { caso contrário }\end{array}$ \\
\hline Porte da firma entrante (log) & Número de empregados na entrada (em logartimo) \\
\hline Porte da firma pai (log) & $\begin{array}{l}\text { Número de empregados da firma pai no ano anterior ao surgimento do spin-off (em } \\
\text { logartimo) }\end{array}$ \\
\hline \multicolumn{2}{|l|}{ Efeitos fixos } \\
\hline Ano de entrada & Ano em que a firma entra no mercado \\
\hline CNAE (2 dígitos) & Classificação Nacional de Atividade Econômica 2.0 \\
\hline
\end{tabular}

Fonte: Elaboração própria.

A primeira variável é o porte das firmas. Existem diferenças de crescimento entre firmas pequenas e grandes. $\mathrm{O}$ crescimento de firmas menores está muito relacionado com sua sobrevivência, conforme aponta Coad (2007). Já as firmas grandes, ainda segundo o autor, "podem ter os objetivos de sobrevivência, crescimento e lucro separados e, até mesmo, conflitantes".

A segunda variável é o indicador de SIMPLES. O baixo crescimento pode não estar relacionado a atributos da firma, mas a uma opção realizada pela firma acerca do seu regime tributário de arrecadação, neste caso, a escolha pelo Simples Nacional. Assim, pode ocorrer que das empresas sobreviventes, determinados entrantes podem apresentar uma maior adesão ao SIMPLES. Pois como destaca Paes e 
Almeida (2009), "em vez de estimular o desenvolvimento e o crescimento das empresas, o Simples estaria favorecendo o nanismo tributário". Daí a importância de se realizar o controle por este tipo de variável.

A terceira é o porte da firma pai. Andersson e Klepper (2013) encontraram evidências da influência do tamanho da firma pai no desenvolvimento de spin-offs. Segundo os autores, quanto maior o porte da firma pai, maior a taxa de crescimento de spin-offs. Para tornar os controles ainda mais refinados, usaremos também esta variável.

A possibilidade de se comparar os resultados com a literatura nacional e internacional também motivou o uso de diversas das variáveis citadas. O uso de dotações iniciais de capital humano foi empregada por todos os trabalhos citados no Quadro 2.1 de Revisão da literatura. Além disso, o controle através da variável de conexão prévia entre os empregados (HHI), variável proposta por Sarada e Tocoian (2018) com os dados do Brasil, permitirá sabermos se a informação observável do tipo de spin-off ainda contribui para explicar a diferença de crescimento entre tais firmas.

Variáveis dependentes. Os modelos de sobrevivência (modelos 1, 2, 6 e 7) possuem como variável dependente uma dummy que indica 1 , se a empresa nascida em $t$ sobrevive em $t+3$ ou $t+6$, e indica 0 , caso contrário.

Nos modelos de crescimento (modelos 3, 4, 8 e 9), no intuito de se reduzir os efeitos de regressão a média, utiliza-se como variável dependente a taxa obtida da equação (2), que apresenta a razão entre aumento do número de empregados das firmas sobreviventes no período e a média aritmética do tamanho médio desta firma no mesmo período.

Já nos modelos de gazelas (modelos 5 e 10), a variável dependente é uma dummy que indica 1, se a empresa nascida em $t$ se transforma em gazela 3 anos depois, e indica 0 , caso contrário.

Utiliza-se para estimar os parâmetros dos modelos acima o método OLS (Ordinary Least Squares).

\section{ANÁLISE DOS RESULTADOS}

As estimativas para análise de sobrevivência, crescimento e gazela são apresentadas na Tabela 6.1. A primeira parte da tabela (modelos 1 a 5) considera os três tipos de entrantes e permite avaliar como os tipos de spin-offs se comportam em relação aos demais entrantes (categoria omitida). A segunda parte tabela (modelos 6 a 10) considera apenas os spin-offs, mas permite que sejam comparados diretamente entre si seus tipos pulled (categoria omitida) e pushed, bem como sejam adicionados controles exclusivos de spin-offs, tais como variáveis relativas à firma pai e ao relacionamento prévio dos empregados. Com isto, é possível avaliar se pulled spin-off brasileiras desempenham melhor do que suas contrapartes pushed e como elas são em relação às demais firmas entrantes.

Vejamos primeiramente os modelos 1 a 4 de sobrevivência e de crescimento, segundo as dotações iniciais de capital humano e características ao nível da firma.

Começando pelas características ao nível da firma, o resultado revela que, mesmo após os diversos controles, ambos os tipos de spin-offs apresentam maior taxa de sobrevivência do que os demais entrantes. Pulled e pushed spin-offs possuem uma probabilidade de sobreviverem no curto prazo, respectivamente, 7,8 p.p. e 5,5 p.p maior do que as demais entrantes. Já a análise dos determinantes de crescimento mostra que apenas pulled spin-off cresce a taxas maiores do que os demais entrantes, em média, cresce 11,0 p.p. acima em um horizonte de 3 anos. Em contrapartida, pushed spin-off cresce no curto prazo 3,0 p.p. a menos do que os demais entrantes ${ }^{19}$.

Os resultados estão em linha com os trabalhadores realizados para Brasil (MUENDLER et al., 2012; SARADA e TOCOIAN, 2018) e Alemanha (FACKLER et al., 2016); parcialmente alinhados com os resultados da Dinamarca (ERIKSSON e KUHN, 2006) e Suécia (ANDERSSON e KLEPPER, 2013), uma vez que nesses países, pulled spin-off possui maior taxa de sobrevivência e de crescimento do que os demais entrantes, porém os dados para pushed spin-offs não são estatisticamente significativos; e

\footnotetext{
${ }^{19}$ No modelo com uma dummy de spin-off (sem detalhar nos seus tipos) e que tem como baseline a dummy demais entrantes mostra que spin-offs (como um todo) apresentam maiores taxas de sobrevivência e de crescimento do que demais entrantes, com significância estatística e p-valor $<0.01$.
} 
encontra-se o contrário do resultado de Portugal (ROCHA, 2014), que conclui pushed spin-off apresentarem maior probabilidade de sobrevivência do que sua contraparte pulled e nada se pode afirmar com relação ao crescimento (rever Quadro 2.1).

Algumas conjecturas podem ser levantadas para explicar as divergências. O fato de pushed spinoffs na Dinamarca e Suécia não serem estatisticamente significativos, em grande medida, pode ser reflexo da maneira como os autores identificam pushed spin-off. Para eles, o evento do empregado que se movimenta "to an entry [firm] which fulfils the conditions of our spin-off definition, except that initial size is larger than ten employees (ERIKSSON e KUHN, 2006, p. 1029)" é considerado divested firm. Desse modo, o que consideramos no trabalho como pushed spin-off que na entrada possui 11 a 100 empregados, os autores consideram como divested. Mas como mostrado no estudo da Suécia, divested firms possuem, com significância estatística, maior probabilidade de sobrevivência do que as demais entrantes. Assim, se os autores tivessem analisado divested firms como pushed spin-off, possivelmente a taxa de sobrevivência de pushed spin-off em relação às demais entrantes também seria estatisticamente significante. A explicação para estatística não significante no comportamento do crescimento deve seguir na mesma linha. 
Tabela 6.1 - Resultados estimados para todos os tipos de firmas.

TODOS OS ENTRANTES

\begin{tabular}{|c|c|c|c|c|c|c|c|c|c|c|}
\hline & $\begin{array}{c}\text { (1) } \\
\text { Sobrev. } \\
\text { em } t+3\end{array}$ & $\begin{array}{c}(2) \\
\text { Sobrev. } \\
\text { em } t+6\end{array}$ & $\begin{array}{c}(3) \\
\text { Cresc. } \\
\text { em } t+3\end{array}$ & $\begin{array}{c}\text { (4) } \\
\text { Cresc. } \\
\text { em t+6 }\end{array}$ & $\begin{array}{c}(5) \\
\text { Gazela } \\
\text { em } t+3\end{array}$ & $\begin{array}{c}\text { (6) } \\
\text { Sobrev. } \\
\text { em } t+3\end{array}$ & $\begin{array}{c}(7) \\
\text { Sobrev. } \\
\text { em } t+6\end{array}$ & $\begin{array}{c}(8) \\
\text { Cresc. } \\
\text { em } t+3\end{array}$ & $\begin{array}{c}\text { (9) } \\
\text { Cresc. } \\
\text { em } t+6\end{array}$ & $\begin{array}{c}(10) \\
\text { Gazela } \\
\text { em } t+3\end{array}$ \\
\hline \multicolumn{11}{|c|}{ Características ao nível das firmas } \\
\hline Indicador de demais entrantes & [Baseline] & [Baseline] & [Baseline] & [Baseline] & [Baseline] & - & - & - & - & - \\
\hline Indicador de pulled spin-off & $\begin{array}{c}0.0782^{* * *} \\
(0.0027)\end{array}$ & $\begin{array}{c}0.0812^{\star \star \star} \\
(0.0042)\end{array}$ & $\begin{array}{c}0.1102^{* * *} \\
(0.0051)\end{array}$ & $\begin{array}{c}0.0987^{\star * *} \\
(0.0089)\end{array}$ & $\begin{array}{c}0.0299^{\star * *} \\
(0.0030)\end{array}$ & [Baseline] & [Baseline] & [Baseline] & [Baseline] & [Baseline] \\
\hline Indicador de pushed spin-off & $\begin{array}{c}0.0551^{\star * *} \\
(0.0038)\end{array}$ & $\begin{array}{c}0.0517^{\star \star \star} \\
(0.0057)\end{array}$ & $\begin{array}{c}-0.0302^{* * *} \\
(0.0071)\end{array}$ & $\begin{array}{c}-0.0527^{* * *} \\
(0.0121)\end{array}$ & $\begin{array}{c}-0.0683^{\star * *} \\
(0.0041)\end{array}$ & $\begin{array}{c}-0.0497^{* * *} \\
(0.0048)\end{array}$ & $\begin{array}{c}-0.0668^{\star \star *} \\
(0.0081)\end{array}$ & $\begin{array}{c}-0.0797^{\star \star \star} \\
(0.0094)\end{array}$ & $\begin{array}{c}-0.0806^{* * *} \\
(0.0173)\end{array}$ & $\begin{array}{c}-0.0488^{\star * \star} \\
(0.0056)\end{array}$ \\
\hline Indicador de SIMPLES tributário & $\begin{array}{c}0.0305^{\star \star *} \\
(0.0019)\end{array}$ & $\begin{array}{c}0.0315^{\star \star \star} \\
(0.0029)\end{array}$ & $\begin{array}{c}-0.0744^{* * *} \\
(0.0037)\end{array}$ & $\begin{array}{c}-0.1176^{* * *} \\
(0.0066)\end{array}$ & $\begin{array}{c}-0.0534^{* * *} \\
(0.0022)\end{array}$ & $\begin{array}{c}0.0168^{\star * *} \\
(0.0046)\end{array}$ & $\begin{array}{l}-0.0033 \\
(0.0078)\end{array}$ & $\begin{array}{c}-0.0706^{\star \star *} \\
(0.0089)\end{array}$ & $\begin{array}{c}-0.1118^{* * *} \\
(0.0166)\end{array}$ & $\begin{array}{c}-0.0521^{* \star *} \\
(0.0053)\end{array}$ \\
\hline Porte da firma entrante (log) & $\begin{array}{c}0.0316^{\star \star *} \\
(0.0013)\end{array}$ & $\begin{array}{c}0.0207^{* \star *} \\
(0.0020)\end{array}$ & $\begin{array}{c}-0.1443^{* * *} \\
(0.0025)\end{array}$ & $\begin{array}{c}-0.1875^{\star * *} \\
(0.0045)\end{array}$ & $\begin{array}{c}-0.0689^{* * *} \\
(0.0015)\end{array}$ & $\begin{array}{c}0.0407^{* * *} \\
(0.0030)\end{array}$ & $\begin{array}{c}0.0264^{\star \star \star} \\
(0.0051)\end{array}$ & $\begin{array}{c}-0.1758^{\star \star *} \\
(0.0058)\end{array}$ & $\begin{array}{c}-0.2351^{* * *} \\
(0.0109)\end{array}$ & $\begin{array}{c}-0.1117^{\star * *} \\
(0.0035)\end{array}$ \\
\hline Indicador de spinoff no mesmo seto & r da firma pa & & & & & $\begin{array}{l}0.0094^{\star \star} \\
(0.0045)\end{array}$ & $\begin{array}{l}0.0198^{* *} \\
(0.0077)\end{array}$ & $\begin{array}{c}0.0639^{\star \star *} \\
(0.0088)\end{array}$ & $\begin{array}{c}0.0658^{\star * *} \\
(0.0164)\end{array}$ & $\begin{array}{c}0.0201^{* * *} \\
(0.0053)\end{array}$ \\
\hline Porte da firma pai (log) & & & & & & $\begin{array}{c}-0.0181^{* * *} \\
(0.0015)\end{array}$ & $\begin{array}{c}-0.0224^{\star \star *} \\
(0.0027)\end{array}$ & $\begin{array}{c}0.0515^{\star \star *} \\
(0.0030)\end{array}$ & $\begin{array}{c}0.0593^{\star * *} \\
(0.0060)\end{array}$ & $\begin{array}{c}0.0384^{* * *} \\
(0.0018)\end{array}$ \\
\hline \multicolumn{11}{|c|}{ Relacionamento prévio entre empregados } \\
\hline HHI (Sarada e Tocoian) & & & & & & $\begin{array}{c}0.0421^{\star * \star} \\
(0.0099)\end{array}$ & $\begin{array}{c}0.1240^{\star \star \star} \\
(0.0167)\end{array}$ & $\begin{array}{c}-0.0690^{\star \star \star} \\
(0.0192)\end{array}$ & $\begin{array}{c}-0.1238^{\star * *} \\
(0.0352)\end{array}$ & $\begin{array}{c}-0.1639^{\star * *} \\
(0.0115)\end{array}$ \\
\hline \multicolumn{11}{|c|}{ Dotação inicial de capital humano dos empregados } \\
\hline Idade média (anos) & $\begin{array}{c}-0.0009^{* * *} \\
(0.0002)\end{array}$ & $\begin{array}{c}-0.0018^{\star \star *} \\
(0.0003)\end{array}$ & $\begin{array}{c}-0.0056^{* * *} \\
(0.0003)\end{array}$ & $\begin{array}{c}-0.0082^{* \star *} \\
(0.0006)\end{array}$ & $\begin{array}{c}-0.0036^{\star \star *} \\
(0.0002)\end{array}$ & $\begin{array}{l}-0.0001 \\
(0.0004)\end{array}$ & $\begin{array}{l}-0.0001 \\
(0.0007)\end{array}$ & $\begin{array}{l}-0.0003 \\
(0.0008)\end{array}$ & $\begin{array}{l}-0.0036^{\star \star} \\
(0.0016)\end{array}$ & $\begin{array}{l}-0.0005 \\
(0.0005)\end{array}$ \\
\hline Share dos mais escolarizados (\%) & $\begin{array}{c}0.0559^{* * *} \\
(0.0071)\end{array}$ & $\begin{array}{c}0.0684^{\star * *} \\
(0.0109)\end{array}$ & $\begin{array}{c}0.1261^{\star * *} \\
(0.0134)\end{array}$ & $\begin{array}{c}0.1764^{\star * \star} \\
(0.0235)\end{array}$ & $\begin{array}{c}0.0767^{\star * *} \\
(0.0078)\end{array}$ & $\begin{array}{c}0.0425^{\star * *} \\
(0.0155)\end{array}$ & $\begin{array}{c}0.0250 \\
(0.0266)\end{array}$ & $\begin{array}{l}0.0705^{\star *} \\
(0.0295)\end{array}$ & $\begin{array}{l}0.0977^{*} \\
(0.0546)\end{array}$ & $\begin{array}{c}0.0530^{\star * *} \\
(0.0176)\end{array}$ \\
\hline Share de homens (\%) & $\begin{array}{l}-0.0023 \\
(0.0032)\end{array}$ & $\begin{array}{c}0.0172^{\star \star \star} \\
(0.0049)\end{array}$ & $\begin{array}{l}0.0127^{\star *} \\
(0.0063)\end{array}$ & $\begin{array}{c}0.0343^{\star * *} \\
(0.0110)\end{array}$ & $\begin{array}{c}0.0471^{\star * *} \\
(0.0036)\end{array}$ & $\begin{array}{c}0.0017 \\
(0.0084)\end{array}$ & $\begin{array}{c}0.0217 \\
(0.0142)\end{array}$ & $\begin{array}{c}0.0562^{\star \star \star} \\
(0.0161)\end{array}$ & $\begin{array}{c}0.1206^{\star \star \star} \\
(0.0299)\end{array}$ & $\begin{array}{c}0.0698^{\star \star *} \\
(0.0096)\end{array}$ \\
\hline Share de primeiro emprego (\%) & $\begin{array}{c}0.0191^{* * *} \\
(0.0039)\end{array}$ & $\begin{array}{c}0.0032 \\
(0.0059)\end{array}$ & $\begin{array}{c}-0.0693^{* * *} \\
(0.0077)\end{array}$ & $\begin{array}{c}-0.0604^{* * *} \\
(0.0134)\end{array}$ & $\begin{array}{c}-0.0144^{\star * *} \\
(0.0045)\end{array}$ & $\begin{array}{c}-0.0269^{\star *} \\
(0.0131)\end{array}$ & $\begin{array}{l}-0.0164 \\
(0.0222)\end{array}$ & $\begin{array}{c}0.0018 \\
(0.0257)\end{array}$ & $\begin{array}{c}0.0043 \\
(0.0481)\end{array}$ & $\begin{array}{c}0.0014 \\
(0.0154)\end{array}$ \\
\hline Média salarial (log) & $\begin{array}{c}0.0255^{\star \star *} \\
(0.0026)\end{array}$ & $\begin{array}{c}0.0176^{\star \star \star} \\
(0.0038)\end{array}$ & $\begin{array}{c}0.1133^{\star \star *} \\
(0.0050)\end{array}$ & $\begin{array}{c}0.1229^{\star \star *} \\
(0.0086)\end{array}$ & $\begin{array}{c}0.0517^{\star \star \star} \\
(0.0029)\end{array}$ & $\begin{array}{l}-0.0024 \\
(0.0055)\end{array}$ & $\begin{array}{c}0.0020 \\
(0.0093)\end{array}$ & $\begin{array}{c}0.0710^{\star \star *} \\
(0.0107)\end{array}$ & $\begin{array}{c}0.1022^{\star \star *} \\
(0.0198)\end{array}$ & $\begin{array}{c}0.0271^{* * *} \\
(0.0064)\end{array}$ \\
\hline Constante & $\begin{array}{c}0.4402^{\star * *} \\
(0.0184)\end{array}$ & $\begin{array}{c}0.3895^{\star \star *} \\
(0.0272)\end{array}$ & $\begin{array}{c}-0.2061^{* * *} \\
(0.0357)\end{array}$ & $\begin{array}{l}-0.0258 \\
(0.0612)\end{array}$ & $\begin{array}{c}0.1642^{\star \star \star} \\
(0.0208)\end{array}$ & $\begin{array}{c}0.7423^{\star * \star} \\
(0.0407)\end{array}$ & $\begin{array}{c}0.5910^{\star * *} \\
(0.0677)\end{array}$ & $\begin{array}{l}-0.1315^{\star} \\
(0.0791)\end{array}$ & $\begin{array}{l}-0.1023 \\
(0.1445)\end{array}$ & $\begin{array}{c}0.2501^{\star * *} \\
(0.0472)\end{array}$ \\
\hline Obs. & 312.259 & 158.043 & 217.856 & 86.532 & 217.856 & 42.891 & 19.723 & 33.112 & 12.331 & 33.112 \\
\hline R2 Ajustado & 0.0338 & 0.0314 & 0.0439 & 0.0484 & 0.0430 & 0.0309 & 0.0342 & 0.0665 & 0.0787 & 0.0889 \\
\hline $\mathrm{F}$ & 261.57 & 98.57 & 563.44 & 286.12 & 453.39 & 31.07 & 15.91 & 138.11 & 66.12 & 186.61 \\
\hline Prob $>F$ & 0.0000 & 0.0000 & 0.0000 & 0.0000 & 0.0000 & 0.0000 & 0.0000 & 0.0000 & 0.0000 & 0.0000 \\
\hline \multicolumn{11}{|l|}{ Efeitos Fixos } \\
\hline CNAE (2 digitos) $x$ Ano de entrada & 606 & 346 & 599 & 339 & 599 & 477 & 238 & 468 & 225 & 238 \\
\hline
\end{tabular}

Fonte: Elaboração própria a partir dos dados da RAIS Empregado 2004-2015.

Notas: Mais escolarizados são empregados com pelo menos o nível superior. A firma é identificada como spin-off se $25 \%$ ou mais de seus empregados vierem de uma mesma firma antecessora (firma pai). Se o pai continuar vivo, tem-se pulled spin-off, caso contrário, tem-se um pushed spin-off. Regressão com erros padrão robusto entre parênteses. *** p<0.01, ** p<0.05, * $\mathrm{p}<0.1$.

A opção pelo regime de arrecadação tributária do SIMPLES indica que ela contribui para taxas maiores de sobrevivência, mostrando-se como uma política econômica acertada em prol de reduzir as barreiras de entradas para novas firmas e estimular a competição. Por outro lado, o SIMPLES se torna um importante limitante (ou desestímulo) para o crescimento da firma, reforçando a visão de Paes e Almeida (2009) a qual tal instrumento tributário contribui para o "nanismo tributário".

Os resultados para o porte inicial da firma seguem a corrente majoritária da literatura. Maior tamanho contribui para maiores taxas de sobrevivência e que não necessariamente se traduzem em crescimento.

Com relação a dotação inicial de capital humano dos empregados, tem-se que novas firmas com empregados mais jovens, com maior nível de instrução e com maior produtividade no mercado de trabalho (proxy através da média salarial) apresentam maiores probabilidade de sobrevivência e taxa de 
crescimento, tanto no curto (acumulado de 3 anos) quanto no médio prazos (acumulado de 6 anos). Observa-se ainda que o efeito da idade e escolaridade parecem ${ }^{20}$ ainda mais importantes no médio prazo, ao contrário da média salarial. Por exemplo, um ano a menos na idade média dos empregados faz com que a probabilidade de sobrevivência da firma aumente 0,09 p.p. no curto prazo e 0,18 p.p. no médio prazo. Por outro lado, a média salarial parece ter maior relevância no curto prazo. O efeito de um aumento de $1 \%$ na média salarial faz com que o incremento na probabilidade de sobrevivência seja 2,5 p.p. no curto prazo e no médio prazo o incremento seja menor, no valor de 1,8 p.p. No que diz respeito a análise de crescimento, o comportamento é semelhante, exceto que média salarial não decresce no médio prazo.

A RAIS Empregado também identifica os empregados que estão no primeiro emprego com carteira assinada. Através desta informação tem-se que firmas entrantes com maior proporção desses empregados sobrevivem mais, o que de algum modo, está relacionado com o fato de serem mais jovens. Essa juventude pode significar colaboradores menos experientes, porém mais bem preparados. Esse melhor preparo pode ser resultado de novas ferramentas ou técnicas aprendidas, assim como estarem mais abertos a novas tecnologias. Contudo, no médio prazo, essa variável que indica o primeiro emprego deixa de ser estatisticamente significante para sobrevivência da firma. Para o crescimento, ela inibe o crescimento da firma entrante em ambos os períodos de observação.

Quanto à proporção de homens, observa-se em geral um efeito positivo sobre a sobrevivência e o crescimento. Exceto no curto prazo para sobrevivência o qual esse efeito não é estatisticamente significativo.

Em seguida, temos os modelos 5 a 9 que incorporam variáveis relacionadas exclusivamente a spin-offs. Assim, com controles mais refinados, é possível afirmar com maior segurança a superioridade (ou não), em termos de desempenho, de pulled spin-off sobre pushed spin-off.

Quanto a características ao nível das firmas, encontra-se evidência empírica de que pushed spinoff apresenta menores taxas de sobrevivência e de crescimento, com significância estatística para ambos todos os coeficientes de curto e médio prazo. Assim, a dinâmica das spin-offs brasileiras corrobora as evidências empíricas da literatura internacional, em que pulled spin-off performa melhor do que pushed spin-off.

O SIMPLES tributário, por sua vez, perde significância no médio prazo de sobrevivência, mas continua contribuindo de forma expressiva como característica limitante ao crescimento. E o porte inicial da firma mantém-se como determinante de maior probabilidade de sobrevivência, mas com contribuição negativa ao crescimento da firma.

Um diferencial dos spin-offs em relação aos demais entrantes é a existência de uma firma pai como fonte de recursos humanos, no sentido de Penrose (1959). Por esta razão, são avaliadas três variáveis: indicador se spin-off entrou pertence ao mesmo setor da firma pai, a influência do porte da firma pai e a intensidade do relacionamento prévio entre empregados.

Verifica-se que continuar no mesmo setor da firma pai tem um efeito positivo tanto na sobrevivência quanto no crescimento, independentemente do horizonte temporal. Estes resultados estão em linha com o restante da literatura de spin-off de empregados (SARADA e TOCOIAN, 2018; ROCHA, 2014; ANDERSSON e KLEPPER, 2013) e reforçam a teoria de que a transferência de conhecimento específico herdada contribui para melhor performance da firma (AGARWAL et al., 2004).

Quanto ao porte da firma pai no ano anterior à entrada do spin-off, mostra-se que ele apresenta efeito opostos para sobrevivência e crescimento. Quanto maior o tamanho da firma pai, menor probabilidade de sobrevivência do spinoff. Porém, uma vez que a firma sobrevive, o tamanho da firma pai tem efeito positivo sobre o crescimento. Andersson e Klepper (2013) e Sarada e Tocoian (2018) chegam ao mesmo resultado. Estes autores apontam que o resultado está consistente com a noção de que vir de firmas pequenas é mais benéfica para a sobrevivência. Porém, que a experiência adquirida nelas não se

\footnotetext{
${ }^{20} \mathrm{Na}$ teoria, como a amostra entre os períodos de análise $\mathrm{t}+3$ e t+6 é distinta, a comparação poderia ser feita. Porém, como há uma importante interseção de empresas entre essas amostras (todas as firmas nascidas de 2006 a 2009) e supondo que o perfil delas não tenha mudado significativamente de 2010 a 2012, assumiremos que é possível tal comparação.
} 
traduz em crescimento, seja pela própria escolha de se manter pequeno ou pela falta de habilidade para aumentar de tamanho.

Por fim, o índice de conexão prévia de empregados, inspirado no HHI e proposto por Sarada e Tocoian (2018), indica que quanto mais conectados são os empregados (isto é, vieram da mesma firma), maior a taxa de sobrevivência. Em contrapartida, no que diz respeito ao crescimento de número de empregados, o indicador tem um efeito negativo. Apesar de o resultado ser contra intuitivo, o estudo Rocha (2014) pode dar uma pista porque isto acontece. Segundo a autora, spin-offs que contratam um maior share de co-workers no momento de entrada tendem a contratar no futuro menos novos empregados, de modo que ajustes na mão de obra dessas firmas são menos frequentes, ou porque começam com uma força de trabalho mais estável ou porque eles identificam desde cedo os "melhores" empregados.

Com respeito aos determinantes para os modelos 5 e 10, que avalia a probabilidade dos entrantes se tornarem empresas gazelas, verifica-se coeficientes com sinais e significância estatística idênticos, aos modelos de crescimento de curto (modelo 3) e médio (modelo 8) prazos. Tem-se ainda que, após os controles, a probabilidade de um pulled spin-off e pushed spin-off crescerem $10 \%$ ao ano nos três primeiros anos de vida é, respectivamente, 3,0 p.p. acima e 6,8 p.p. abaixo do que os demais entrantes.

\section{CONCLUSÃO}

A partir do amplo conjunto de dados longitudinais em painel da RAIS identificada, que compreende o universo de todas as empresas formalmente constituídas no país e que relaciona empregados a empregadores durante o período de 2006 a 2015, busca-se analisar como spin-offs de empregados evoluem no curto/médio prazo. Além disso, avaliar se no Brasil a performance dos tipos de spin-off estão em linha com a maior parte da literatura internacional, isto é, pulled spin-off apresentando maior taxa de sobrevivência e de crescimento do que às pushed spin-off. Ainda, no contexto de crescimento de firmas, estuda-se a probabilidade de spin-offs se transformarem em empresas gazelas, firmas com até 5 anos de idade e crescimento médio de $10 \%$ ao ano nos últimos três anos.

Baseado nos trabalhos de Muendler et al. (2012) e Sarada e Tocoian (2018), estabelece-se um critério para identificação de spin-off de empregados: firmas entrantes com mínimo 5 e no máximo 100 empregados as quais $25 \%$ ou mais desses empregados veem de uma mesma firma antecessora (firma pai); caso a firma pai sobreviva após a abertura do spin-off, tem-se o que chamamos de pulled spin-off (ou spin-off de oportunidade), caso contrário, pushed spin-off (ou spin-off de necessidade). A partir dessa definição, verifica-se que spin-offs representaram, entre 2006 a 2015, 14,2\% a 19,8\% do total de empresas entrantes, onde aproximadamente $2 / 3$ delas são pulled spin-off. Ainda, verifica-se que a formação de spinoffs apresenta uma importante correlação negativa com a atividade econômica, inclusive com tendência de crescimento nos últimos anos, resultado da crise econômica que se inicia em 2014.

A distribuição setorial de spin-offs segue, em linhas gerais, a distribuição das demais firmas entrantes, embora haja alguns desvios, como por exemplo, estar mais concentrada no setor de serviços. A tendência geral de terceirização das atividades ou da desverticalização das empresas parece contribuir com este fenômeno.

Possivelmente, pela primeira vez, relaciona-se spin-off de empregados com empresas gazelas. Geralmente, os estudos relacionam spin-offs acadêmicas a gazelas. Observa-se que cerca de 1/3 dos spinoffs se transformam gazelas após três anos de vida e que esse percentual é superior, com significância estatística, ao mesmo percentual das demais firmas entrantes.

Outra novidade é o uso de indicador de arrecadação tributária SIMPLES Nacional como variável explicativa de desempenho, que se mostra um importante instrumento de política econômica, ao aumentar a taxa de sobrevivência das firmas. Porém, como era de se esperar, esse mecanismo também desestimula o crescimento das firmas e, naturalmente, a geração de empregos.

Finalmente, verifica-se que, mesmo após o uso de inúmeros controles, os resultados indicam que spin-offs brasileiras apresentam taxas de sobrevivência e de crescimento superiores à taxa dos demais entrantes, sendo que o mesmo não ocorre quando se detalha pelos tipos de spin-off. Ambas pulled $\mathrm{e}$ 
pushed spin-off possuem maior probabilidade de sobrevivência. Porém, com relação ao crescimento, pushed spin-off cresce a taxas inferiores que os demais entrantes, ao contrário das pulled spin-offs. Além disso, encontra-se evidência empírica de que pushed spin-offs apresentam desempenho consistentemente superior a pushed spin-offs, o que está em linha com a maior parte da literatura internacional.

Diante dos resultados deste trabalho, em se tratando de características observáveis, a identificação pulled e pushed spin-offs se faz necessária na definição de estratégias organizacionais, em discussões sobre cláusulas de não-competição (spin-off não concorrer com empresa pai) e em análises de risco de crédito e de mercado de capitais.

Apesar do esforço, perguntas sobre a dinâmica das spin-off de empregados brasileiras continuam em aberto. Possíveis estudos para o Brasil seriam avaliar o efeito no desempenho dos spin-offs da proximidade geográfica com a firma pai; estudar se desempenho de spin-off é condicional ao crescimento da firma pai, não apenas se sobreviveu; e, dado que a majoritária literatura sobre spin-off se refere a spinoffs acadêmicas, identificar de forma censitária na RAIS tais firmas e comparar sua performance com a de spin-offs corporativos/empreendedores.

\section{REFERÊNCIAS BIBLIOGRÁFIAS}

AHMAD, N.; SEYMOUR, R. G. Defining entrepreneurial activity: definitions supporting frameworks for data collection. Paris: Organisation for Economic Co-operation and Development OECD, 2008. 18 p. (OECD statistics working papers, 2008/1). Disponível em:<https://papers.ssrn.com/sol3/papers.cfm?abstract_id=1090372>. Acesso em: ago. 2018

AGARWAL, Rajshree et al. Knowledge transfer through inheritance: Spin-out generation, development, and survival. Academy of Management journal, v. 47, n. 4, p. 501-522, 2004.

AGARWAL, Rajshree et al. What do I take with me? The mediating effect of spin-out team size and tenure on the founder-firm performance relationship. Academy of Management Journal, v. 59, n. 3, p. 1060-1087, 2016.

ANDERSSON, Martin; KLEPPER, Steven. Characteristics and performance of new firms and spin-offs in Sweden. Industrial and corporate change, v. 22, n. 1, p. 245-280, 2013.

BAPTISTA, Rui; KARAÖZ, Murat; MENDONÇA, Joana. The impact of human capital on the early success of necessity versus opportunity-based entrepreneurs. Small Business Economics, v. 42, n. 4, p. 831-847, 2014.

BENEDETTO, Gary et al. Using Worker Flows in the Analysis of the Firm. Center for Economic Studies, US Census Bureau, Technical Paper 2003-09, 2004.

BHIDÉ, Amar V. The origin and evolution of new businesses. Oxford University Press, 2003.

BUENSTORF, Guido. Opportunity spin-offs and necessity spin-offs. Papers on economics and evolution, 2007.

CADASTRO central de empresas 2016. In: IBGE. Sidra: sistema IBGE de recuperação automática. Rio de Janeiro, [2018]. tab. 992. Disponível em:< https://sidra.ibge.gov.br/tabela/992>. Acesso em: jun. 2019.

COAD, Alex. Firm growth: A survey. Papers on Economics and Evolution 2007-03, Max Planck Institute of Economics, Evolutionary Economics Group, Jena, Germany, 2007

DEMOGRAFIA das empresas 2011. Rio de Janeiro: IBGE, 2013. 147 p. Disponível em: < https://biblioteca.ibge.gov.br/index.php/biblioteca-catalogo?view=detalhes\&id=265422>. Acesso em: mai. 2019.

ERIKSSON, Tor; KUHN, Johan Moritz. Firm spin-offs in Denmark 1981-2000: patterns of entry and exit. International Journal of Industrial Organization, v. 24, n. 5, p. 1021-1040, 2006. 
ESTATÍSTICAS do cadastro central de empresas 2017. Rio de Janeiro: IBGE, 2019. 100 p. Disponível em: <https://biblioteca.ibge.gov.br/index.php/bibliotecacatalogo?view=detalhes\&id=2101658>. Acesso em: jun. 2019.

FACKLER, Daniel; SCHNABEL, Claus; SCHMUCKER, Alexandra. Spin-offs in Germany: characteristics, survival, and the role of their parents. Small Business Economics, v. 46, n. 1, p. 93-114, 2016

FERREIRA, Manuel Portugal et al. Structural and longitudinal analysis of the knowledge base on spin-off research. Scientometrics, v. 112, n. 1, p. 289-313, 2017.

GARVIN, David A. Spin-offs and the new firm formation process. California management review, v. 25, n. 2, p. 3-20, 1983.

HENREKSON, Magnus; JOHANSSON, Dan. Gazelles as job creators: a survey and interpretation of the evidence. Small Business Economics, v. 35, n. 2, p. 227-244, 2010.

KLEPPER, S. Silicon Valley - A chip off the old Detroit bloc, 2007. In: AUDRETSCH, D. B.; STROM, R.; ACS, Z. Entrepreneurship, Growth, and Public Policy. Cambridge UK: Cambridge University Press, 2009, cap. 5.

KLEPPER, Steven; SLEEPER, Sally. Entry by spin-offs. Management science, v. 51, n. 8, p. 1291-1306, 2005.

MUENDLER, Marc-Andreas; RAUCH, James E.; TOCOIAN, Oana. Employee spin-offs and other entrants: Stylized facts from Brazil. International Journal of Industrial Organization, v. 30, n. 5, p. 447-458, 2012.

PAES, Nelson; ALMEIDA, Aloísio. Tributação da pequena empresa e avaliação do Simples. Caderno de Finanças Públicas, v. 9, p. 5-55, 2009.

PENROSE, E. T. The Theory of the Growth of the Firm. Oxford: Basil Blackwell, 1959.

RIBEIRO, E. P.; CORSEUIL, C. H.; COELHO, D. S. C. Using Worker Flows to Measure Firm Dynamics in Brazil - Entry, Exit and Mergers. In: GDEC-CRESSE International Workshop on Advances in Competition Policy Analysis, 2017, Rio de Janeiro. Complete Papers - GDEC-CRESSE International Workshop on Advances in Competition Policy Analysis. Rio de Janeiro: GDEC, 2017. v. 1.

ROCHA, Vera C. B. Entrepreneurship dynamics: entry, survival and firm growth. 2014. Tese (Doutorado) - Economia e Gestão, Faculdade de Economia da Universidade do Porto, Porto, 2014, p. 156-194.

ROCHA, Vera; CARNEIRO, Anabela; VARUM, Celeste. What explains the survival gap of pushed and pulled corporate spin-offs?. Economics Letters, v. 126, p. 127-130, 2015.

SARADA; TOCOIAN, Oana. Is It All About Who You Know? Prior Work Connections and Entrepreneurial Success. Claremont McKenna College Robert Day School of Economics and Finance Research Paper, Fev. 2018. Disponível em: <https://ssrn.com/abstract=2650627>. Acesso em: 5 Out. 2018.

SAP, 2018. Disponível em: <https://www.sap.com/corporate/en/company.html\#overview>. Acesso em: 8 Nov. 2018.

SENDEROVITZ, Martin et al. Four years on-are the gazelles still running? A longitudinal study of firm performance after a period of rapid growth (summary). Frontiers of Entrepreneurship Research, v. 32, n. 12, p. 14, 2012. 